\title{
Physical activity programmes in the workplace and the role of organisational culture: A systematic review of current evidence
}

Received: 19

November 2020 For correspondence: alex.lucas@port.ac.uk

\author{
Alex B Lucas ${ }^{1,2}$, Matthew Wade ${ }^{2}$ and Christopher R. D. Wagstaff ${ }^{1}$ \\ ${ }^{1}$ School of Sport, Health, and Exercise Science, Spinnaker Building, Cambridge Road School of Sport, \\ Portsmouth, P01 2ER, 2ukactive Research Institute, ukactive, 10 Bloomsbury Way, Holborn, London, WC1A 2SL \\ Please cite as: Lucas, B. A, Wade, M., \& Wagstaff, C. (2020). Physical activity programmes in the workplace and \\ the role of organisational culture: A systematic review of current evidence. SportRXiv. \\ https://doi.org/10.31236/osf.io/3wzvu
}

\section{ABSTRACT}

Evidence links physical activity (PA) participation to mental wellbeing and work performance, leading organisations to implement workplace PA programmes. Workplace factors, like organisational culture (OC), have been associated with PA programme implementation, usage, and sustainability. Yet, no synthesis of this work exists, perhaps contributing to the limited consideration of OC in PA programmes. The aim of this review was to examine the knowledge regarding OC and PA workplace programmes and identify literature themes and gaps to provide recommendations for future research and practical implementation. A systematic review of health and social science databases was conducted, with 40 studies reviewed at full text. Study findings indicated that OC manifested through extant themes and influenced programmes through senior leadership, normative behaviours, acceptance and prioritisation, and organisational policies. Programmes varied in length, type, and quality of PA data metrics collected. Recommendations include: using socio-ecological and employeecentred approaches in programme research and development; improving programme measurement and evaluation to expand the evidence-base and; developing tangible guidance for employers to support programme implementation. OC plays an important role in workplace PA programme success, yet evidence informed decisions, improving measurement, and producing clear guidance is required, leading to ongoing research and developing high-quality programmes. 


\section{INTRODUCTION}

Physical activity (PA) participation influences physical health, and mental, social, and economic wellbeing (Babic et al., 2017; Bize et al., 2007; Breuer, 2014; Public Health England, 2016). Being physically active reduces the risk of non-communicable diseases and mental illness, including cardiovascular disease (-35\%), all-cause mortality (-30\%) and depression (-30\%) (Public Health England, 2016). Despite this, in 2018 37\% of the United Kingdom (UK) population reported never doing any exercise or sport (European Commission, 2018) and in $201924.8 \%$ of the UK population remained 'inactive', completing less than 30 minutes of moderate-vigorous intensity PA (MVPA) per week (Sport England, 2019). Physical inactivity has negative costs for society, including being the fourth leading risk factor for global mortality (Public Health England, 2016) and causes of global disease burden (Ding et al., 2016). Furthermore, physical inactivity costs the UK National Health Service (NHS) an estimated £0.9 billion per year (Public Health England, 2016; Scarborough et al., 2011).

Considerable attention is thus focused on increasing PA levels across the UK (Allender et al., 2007), as set out in the 2005 Government's PA plan and illustrated through the 2019 Chief Medical Officer's (CMO) activity guidelines (Davies et al., 2019; Department of Health, 2005). Interventions now exist both within the health and activity sectors (e.g. 'Change4Life', [Public Health England, 2020] and 'We Are Undefeatable', [Sport England, 2020]) and beyond it, such as in the workforce ([FSB, 2020]; Retamal et al., 2011). Workplaces are a popular location for such interventions because they, and the workforce, are recognised as an optimal place to engage employees in PA (Dugdill et al., 2008; NICE, 2008b; Retamal et al., 2011; WHO, 2008). Firstly, workplaces are relevant because of the prolonged time the population spends at work (Cahalin et al., 2015; Flynn et al., 2018). Secondly the established social and communication networks (e.g. between leadership and colleagues) that exist in workplaces mean cultural environments can be created that can aid behaviour change (Plotnikoff et al., 2005). Thirdly, a physically active workforce benefits employers and employees while an inactive workforce is costly. Employee PA participation has been associated to job satisfaction (Conn et al., 2009), fewer sick days (absenteeism) (BHF, 2016; FT, 2019; Merrill et al., 2013; Squires et al., 2012), and greater productivity and reduced presenteeism (Cancelliere et al., 2011; Merrill et al., 2013; PuigRibera et al., 2015). Moreover, inactivity accounted for $14 \%$ of annual sickness absence in the UK in 2019 (FT, 2019) and there is a greater likelihood of early death in those who are inactive working in sendetary, office-based roles (Ekelund et al., 2016).

Despite these benefits, PA is not always included in workplace health programmes and there is a scarsity of high-quality studies focusing on workplace PA promotion (Mackenzie et al., 2018; Taylor et al., 2018), particularly what influences their success and maintenance. However, where they do exist, workplace PA programmes take various forms, and individual, social, environmental, financial or organisational factors have been shown to influence their implementation and uptake (Plotnikoff et al., 2005; Sallis et al., 2008). The latter is of particular interest; organisational factors refer to the way an organisation influences its employees behaviour through the psycho-social environment and the culture of the organisation (Sallis et al., 2008). Organisational culture (OC) is an area of growing interest in influencing workplace PA programmes, and its association to workplace PA programmes has been examined and reported within the academic literature. 
In order to explore this association, we must first consider definitional and conceptual matters regarding OC. OC is not a new concept; it was initially studied in the late 20th century, but Schein, in the 1990s, popularly conceptualised it as a system of shared values, beliefs, and practices engrained across an organisation, which included the unspoken rules, policies, and attitudes held (Schein, 2010). Later accounts of OC viewed this conceptualisation as limiting, claiming it referred to surface phenomena rather than the meanings behind them, and considered OC from a singular perspective rather than something that exhibits different patterns throughout levels of an organisation (Alvesson, 2016). Following this, Alvesson instead coined culture as "a shared and learned world of experiences, meanings, values, and understandings that inform people and are expressed, reproduced, and communicated partly in symbolic form" (p. 15, Alvesson, 2016), broadening Schein's conceptualisation. Alvesson referred to two important elements; firstly socially shared meaning as how objects or phenomenon are interpreted by a group of employees and secondly symbols, as an action that that stands for something else (Alvesson, 2016). As a result Alvesson attempted to capture, in his definition, the multiple layers of OC and the different ways it is exhibited in a single organisation. Other broader perspectives also exist, another being the triperspective put forward by Martin (1992) which sees culture through three lenses know as integration, differentiation and fragmentation. The integration perspective places emphasis on the shared and universal aspects of culture, seen to be uniform across an organisation. The differentiation perspective sees a culture as comprising 'macro-cultures', where interpretations and perspectives differ dependent on level, department or role. The final perspective, the fragmentation perspective, assumes that OCs can never be fully defined and they remain ambiguous (Mumby, 1994). It is common for researchers to adopt only one of these three perspectives, yet Martin (1992) states that all three should be considered within a single organisation to understand culture it its fullest. These latter interpretations of culture have gained in popularity amongst OC researchers in the area of sport and physical activity (Wagstaff \& Burton-Wylie, 2018).

OC, as a complex phenomenon, associates to workplace PA in various ways. For example, researchers have highlighted the importance of integrating PA promotion into workplace OC to encourage long-term behaviour change (Blake \& Lloyd, 2008; Das et al., 2016; Graveling et al., 2008; Huijg et al., 2015; Mackenzie et al., 2018; Malik et al., 2014; Marshall, 2004; Pereira et al., 2015). In her narrative review, Allen (2017) states that certain OCs can drive employees towards unhealthy and inactive behaviours by being unsupportive of and resistant to health initiatives and PA opportunities. Studies exploring employees' perceived barriers and facilitators for engaging in workplace PA indicate that providing PA opportunities does not equate to usage or behaviour change if workplace routines and organisational messages from leadership and colleagues do not reflect PA as part of the OC (Flint et al., 2017; O'leary et al., 2018; Viskum et al., 2015). Das et al. (2016) and Taylor et al. (2018) highlight the important role leadership has in establishing workplace practices that make being active 'the norm' in the OC. Taylor et al. (2018) and Flynn et al. (2018) also highlight that OC extends beyond the role of managers, and should focus on all organisational levels including employees values and beliefs. Employees have positively impacted the culture in their workplace to support PA by acting as workplace champions (Mackenzie et al., 2018), demonstrating that the role they play impacts others PA behaviours. OC also extends to the role of business priority and policy, whereby if the business does not prioritise employee health, wellbeing or PA, through policies or practices, the 
workplace is unlikely to support any behavioural change (Aldana et al., 2012; Mellor \& Webster, 2013). PA behaviour change was found to be low in a workplace that limited PA and health behaviour through a lack of focus in their OC (O'leary et al., 2018). Opposingly, PA behaviour change was more likely to be sustained in a workplace that made attempts to change their OC to focus more on PA messaging (Brakenridge et al., 2018). Overall, there is growing evidence to indicate that OC has a role to play on workplace PA.

Like its definition, OC in relation to workplace PA is a complex relationship. As the above previous literature indicates, many shared cultural practices, like messages, routines, attitudes and beliefs adopted by colleagues and leadership, have the ability to influence PA behaviours in the workplace. Taking the literature reviewed so far, it would appear there is growing acknowledgement of the importance of $\mathrm{OC}$ for the success of workplace PA programmes. The aim of the present review is to further understanding in this area and in order to do this it is necessary to synthesis existing literature. Firstly, we aim to explore how OC impacts workplace PA and how this is explored in the literature to date by highlighting gaps and commonalities. By synthesising research on this topic, we also hope to identify applied recommendations and outline future research priorities to support the practical application of PA in the workplace.

\section{METHOD}

A systematic review was undertaken adopting the preferred reporting items for systematic reviews and meta-analyses (PRISMA) guidelines (Moher et al., 2009).

\section{Search strategy}

Searches were undertaken in August 2020 using four electronic databases (viz. Web of Science Core Collection; PsycINFO; PubMed; Cochrane Library). All reviewed literature was published prior to the COVID-19 pandemic. Further citation searches were carried out by examining the literature referenced in shortlisted articles. The four stage procedure of review and screening outlined by Moher et al. (2009), and the inclusion and exclusions criteria, are shown in the search strategy in Figure 1. The search terms used for database searches were: (organizational culture) OR (organisational culture) OR (workplace culture) AND (workplace physical activity) OR (workplace physical activity intervention) OR (workplace physical activity initiative).

\section{Data extraction and synthesis}

Information was extracted on: 1) study design and data collection methods; 2) setting and participants; 3) intervention(s); 4) outcomes measurements; and 5) results. Studies were compared and critiqued on characteristics, intervention, and key $\mathrm{OC}$ related themes that influenced programme implementation, uptake, and sustainability. 
Figure 1. Search Strategy employed and review

\section{Stage 1: Database}

\begin{tabular}{|c|}
\hline From August, 2020 \\
Total $n=3,071$ \\
PubMed $(n=1,861)$ \\
Web of Science Core Collection $(n=79)$ \\
PsychINFO $(n=1,121)$ \\
Cochrane Library $(n=10)$
\end{tabular}

Additional records identified through other sources $(n=1)$

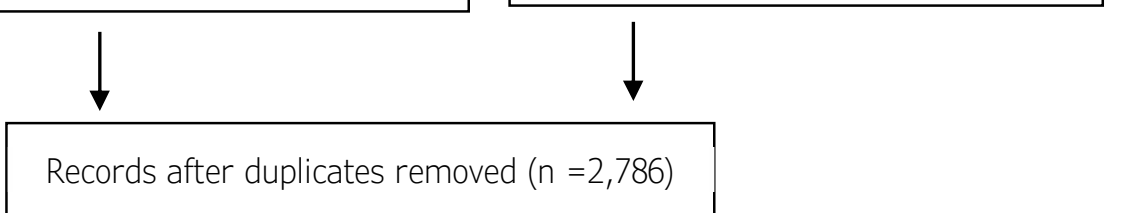

Inclusion Criteria:

Available in English

Evaluation of PA programmes in the workplace

Impact of workplace PA programmes to increase PA Views, perceptions, barriers, facilitators to implementation, adherence, uptake of PA workplace programmes

Explored behaviour change because of PA workplace programmes associated to organizational culture Studied perceptions of workplace culture and PA promotion.



Stage 3: Abstract review

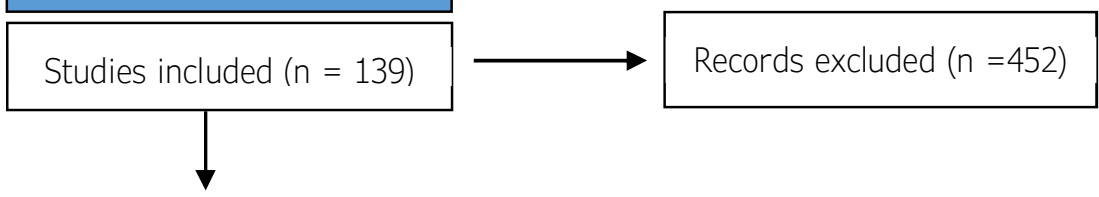

Stage 4: Full text review

Studies included $(n=40)$

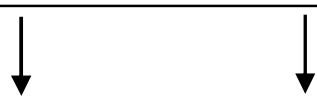

Studies included in literature review

( $n=38)$, including $(n=1)$ additional record

Studies included in background (previous systemic reviews $(n=6)$ )
Records excluded $(n=99)$

Exclusion Criteria:

Text not available in English Focus on sedentary/sitting time instead of PA

Focus on leisure time PA or PA to travel to work

Focus on community-based PA Focus on health benefits of PA in the workplace

Not focused on workplace population (e.g. with students, elite sports) 


\section{Study Characteristics}

Forty studies were reviewed at full paper dating from 1999-2020 (Table 1). Thirty-two (80\%) were published from 2011 to 2020, and 16 (41\%) from 2017 to 2020, indicating a recent growth in publications.

The majority of studies were conducted outside of the UK (68\%) and focused on office-based workplaces in the private, public and third $(n=16)$ or educational $(n=8)$ sectors (Table 2). Data was frequently sampled from employees only $(n=15)$ or from both employees and employers $(n=15)$ (Table 2). There was roughly an even split between qualitative $(n=13)$ and quantitative $(n=12)$ methods used and nine studies used mixed-methods (Table 2). Interviews were the most common form of qualitative method used $(n=13)$ and surveys or questionnaires were the most frequently used quantitative method $(n=19)$. 


\section{(웅}

\section{SportR iv $\begin{aligned} & \text { Part of the Society for Transparency, Preprint } \\ & \text { Openness and Replication in }\end{aligned}$}

Kinesiology (STORK) not peer reviewed

Table 1. Details of all reviewed studies

\begin{tabular}{|c|c|c|c|c|c|}
\hline Author & $\begin{array}{l}\text { Study design \& } \\
\text { data collection }\end{array}$ & $\begin{array}{l}\text { Setting \& } \\
\text { participants }\end{array}$ & Intervention & Relevant measures/topic & Key findings \\
\hline $\begin{array}{l}\text { (Adams et al., } \\
\text { 2017) } \\
(1)\end{array}$ & $\begin{array}{l}\text { Cross-sectional. } \\
\text { Survey \& } \\
\text { interviews. }\end{array}$ & $\begin{array}{l}\text { Five workplaces; } \\
\text { UK. } \\
\text { Employees. }\end{array}$ & $\begin{array}{l}\text { Walking Works } \\
\text { programme. }\end{array}$ & $\begin{array}{l}\text { PA levels (IPAQ-SF). } \\
\text { Programme engagement, } \\
\text { challenges, and impact. }\end{array}$ & $\begin{array}{l}\text { Flexible working hours, walking champions, time } \\
\text { built into day for walking, workplace culture, and } \\
\text { employee-centred approach seen to support } \\
\text { walking behaviour. Job demands, awareness, and } \\
\text { management support were challenges. }\end{array}$ \\
\hline $\begin{array}{l}\text { (Bailey et al., } \\
\text { 2018) } \\
\text { (2) }\end{array}$ & $\begin{array}{l}\text { Cross-sectional. } \\
\text { Interviews. }\end{array}$ & $\begin{array}{l}200 \text { workplaces; } \\
\text { USA. } \\
\text { Supervisors. }\end{array}$ & $\begin{array}{l}\text { Healthiest } \\
\text { Maryland } \\
\text { Businesses } \\
\text { program. }\end{array}$ & $\begin{array}{l}\text { Facilitators and barriers to } \\
\text { implementing PA programs } \\
\text { and policies. }\end{array}$ & $\begin{array}{l}\text { Only informal policies exist to encourage PA, more } \\
\text { so for SMEs (less funding). Senior management } \\
\text { was a key influencing factor. Need to better a) } \\
\text { communicate link between PA and ROI to } \\
\text { encourage businesses buy-in; b) provide guidance } \\
\text { to support businesses. }\end{array}$ \\
\hline $\begin{array}{l}\text { (Banwell et al., } \\
\text { 2016) } \\
\text { (3) }\end{array}$ & $\begin{array}{l}\text { Case study. } \\
\text { Interviews. }\end{array}$ & $\begin{array}{l}\text { SMEs, Australia. } \\
\text { Workers and } \\
\text { managers. }\end{array}$ & $\begin{array}{l}\text { Healthier Work } \\
\text { Program (HWP). }\end{array}$ & Experiences of the HWP. & $\begin{array}{l}\text { HWP practices more likely to be routinised if } \\
\text { managers supported them. Barriers to adopting } \\
\text { change includes culture of long hours. SMEs face } \\
\text { more challenges (e.g. resource and cost). }\end{array}$ \\
\hline $\begin{array}{l}\text { (Blake \& Lloyd, } \\
\text { 2008) } \\
\text { (4) }\end{array}$ & $\begin{array}{l}\text { Narrative review. } \\
\text { N/A }\end{array}$ & N/A & N/A & $\begin{array}{l}\text { Influencing health culture, } \\
\text { best practice for Workplace } \\
\text { Health Programs (WHPs). }\end{array}$ & $\begin{array}{l}\text { Negative attitudes associated to existing 'health } \\
\text { cultures' limit change. Importantly, high-level } \\
\text { managerial support from the outset is essential. }\end{array}$ \\
\hline
\end{tabular}


(Brinkley,

McDermott, et

Quasi-

experimental.

al., 2017)

(5)

(Brinkley, Freeman, et al.,

2017)

(6)

(Chau et al.,

2019)

(7)

Cross-sectional.

Focus groups \& interviews.

12 workplaces, 10 None.

industry sectors,

Australia.

Employees \&

managers.

\section{(Cooper \&}

Cross-sectional.

Barton, 2016)

(8)

Survey \& focus groups.

Higher education

institution, UK.

Employees.

Seattle \&

Baltimore, USA.

2011)

Cross-sectional.

Survey.

(9)

(Edmunds et al., Pre-post

2013)

sport

\section{intervention}

Questionnaire \& focus groups. 12-week team

programme.

Expectations, challenges, barriers to adoption and maintenance.

Workplace motivation, facilitators and obstacles to PA participation.

Workplace culture, barriers and facilitators of changing PA at work.

Self-report PA status, PA levels (IPAQ-SF), perceived barriers/ incentives for workplace PA. of PA promotion strategies \&

17 private/ public/ Six-month $3^{\text {rd }}$ sector Workplace organisations, UK. Activator (WA) Employees.
Explored presence/absence PA levels (IPAQ).

None.

PA levels; impact of WA programme on wellbeing, work performance.
Workplace demands, lack of support, communication of time to take part, leadership role modelling, and culture of non-stop working challenged participation and maintenance.

Workplace culture (norms \& beliefs) predisposed the adoption of workplace team sport. A culture of acceptance created support, trust, encouragement, acted as a facilitator and encouraged flexible working for long-term participation. A culture of 'working non-stop' was an obstacle.

PA was not an explicit strategy priority for workplace health promotion. Perceived manager support, location, and role modelling influenced workplace PA. Activity-promoting solutions at work involved participatory, multicomponent approaches.

University culture impacted workplace PA. Top barriers were lack of time/workload and incentives included culture change (e.g. PA champions, flexible working, manager encouragement). Current university culture perceived as not conducive to PA.

Worksite promotion index was significantly associated with greater PA. Worksite policies designed to promote PA were associated with higher MVPA and recreational PA inside work. Main themes: awareness of PA; sustaining PA behaviour change; embedding PA in the workplace culture. Increased social support and 
(training on PA, exercise

classes).

(Flynn et al., 2018)

(11)

(George et al., 2014)

(12)

Systematic

review.

Database

searches.

Cross-sectional.

$\backslash$ focus groups.

University of

Western Sydney,

Australia.

Employees.

RCT.

Pedometers \&

University, UK.

(Gilson et al., 2008) interviews.

(Gutermuth et al., 2018)

(14)

\section{N/A}

To inform development of ManUp UWS

project, 12-

week internet-

based PA

intervention.

Ten-week RCT

comparing

'walking

routes',

'walking-while-

working' \&

control.

N/A role modelling from activators and colleagues motivated participants to exercise.

Shortlisted papers on culture of health elements.

Explored benefits, motivators and barriers related to PA.

Explored benefits \& barriers of involvement in intervention.

Described PA components of a worksite health promotion intervention and effective strategies.
The most frequently studied culture of health elements were policies and procedures, and communications. Few examples of how culture change affects behaviour change, and direct relationship between PA and culture not specified. Barriers to participant: time, work commitments, lack of opportunity to be active in working hours. Participants believed that PA should be recognised as a legitimate work activity, with support and endorsement from senior staff, embedded within the university culture.

Intervention groups had higher step counts than control. Accepted practice and management culture a sub-theme. Walking while working was difficult to engage in because it was not considered 'normal' by peers.

Common organisational support strategies producing PA improvements included leadership support. Top four PA strategies were 1) information on PA benefits/seminars; 2) organised PA programs; and 3) PA recommendations. Finding reinforces the importance of creating a supportive workplace and culture. 
(Hammerback et al., 2015)

(15)

(Hendriksen et Pre-post cluster al., 2016)

(Jia et al., 2017) Cross-sectional. Questionnaire.

(Latza et al., 2018)

(18)

Cross-sectional. Interviews.

control.

Questionnaire \&

health check.

(Lemon et al. 2009)

(19)

RCT.

Anthropometric

measurements \&
University of

Washington,

Seattle, USA.

Employees.

Dutch insurance

company.

Employees.

Enterprise

workplaces, China.

Unspecified.

Ministry of

Participants

Defense, Germany. previously

Department heads. involved in a

six-month pilot

survey.

Employees. of WHP.

Participants

previously

a WHP.

Five-month

intervention

targeting PA

practices and

activities at

three levels.

None.

Baseline \& six-

month follow

up; ecological

framework

focusing

organisational

and employee

factors.
PA behaviours \& perceptions of WHP.

Work-related factors, health behaviours (e.g. PA).

PA levels (IPAQ-SF) \& workplace health culture.

Explored organisational culture and WHP program success.

PA (IPAQ-LF), organisational commitment to health, coworker normative behaviour of PA.
If WHP was not offered most cited reason was that it was not an organisational priority (not part of OC), company was too small, not accepted from employer.

No significant improvement on MVPA short term. Perceived organisational support increased from baseline (7.4) to post (8.2), but decreased at follow-up (8.0). Work performance and sickness absence improved but no interaction with organisational support or MVPA was undertaken. Workplace health culture was positively associated with PA. Workplace health promotion could focus on improving the health behaviour of leadership over employees, as these ratings were lower.

Introduction of the WHP was top-down from department heads. Mid-management was problematic and acted as a barrier to giving 'permission'. Communication was necessary for success. Activities worked best when employeecentric.

Higher perception of co-worker normative PA behaviours was associated with greater total PA and organisational commitment was negatively associated. Normative behaviour of co-workers can impact PA levels of employees. 
(Lemon et al.,

2014)

(20)

Pre-post RCT.

Biometric

assessments \&

survey.

(Lier et al., 2019)

(21)

Exploratory.

Survey/corporate fitness platform.

White and blue collar companies from six industries, Germany.

Companies. schools,

Participants

(Mazzola et al.,

Cross-sectional.

Survey and

University, USA.

Employees.

interviews.

(22)

Narrative review. N/A

(Michaels \&

Greene, 2013)

(23)

(Onufrak et al., 2018)

(24)
Cross-sectional.

Survey.

ConsumerStyles survey 2013, 50

states, USA.

Employees. Baseline, 12 \& 24-month.

Social-

ecological

approach

(champions, PA

facilities,

campaigns,

walking

groups).

had access to

Organisational program support, leadership,

willingness. program. Data at two \& 20

months.

None.

Implementation of physical environment and policy intervention strategies.

\section{Exercise behaviours and} frequency. Barriers and facilitators to workplace exercise.

Definitions of WHP, organisational change models, how to plan a WHP and evidence-based strategies.

None.

Policy and worksite PA (e.g. time to be active, PA programmes, organisational support).
The intervention was integrated into organisational facilities, structure, and culture. Of the three levels targeted, policy change was the most challenging area to influence administrators not willing/able to make formal policy to allow exercise during work days.

Organisational program support $(\beta=0.051, p<$ 0.001) significant predictor for program enrolment. Lack of leadership willingness to actively and passively support the programmes acted as a participation barrier. Establishment of a health culture as priority is essential.

Barriers were lack of options/social influences and workload. Facilitators included time to exercise. Social support and flexible working aided PA efforts.

Evidence-based PA strategies: providing PA facilities (e.g. changing), social support, information (e.g. signs, flexible working). WHP success focused around culture: 1) engaging leadership, 2) aligning to organisational identity, 3) ensuring program is relevant \& accessible, 4) communication.

Larger employers more likely to offer PA opportunities than smaller (40.6\% vs $23.3 \%$ ). Top policies: on-site facilities, employer supports, support taking time for PA. Larger employers 
(Payne et al.,

2018)

(25)

Longitudinal.

Biometric

screenings \&

surveys.

(Pronk \& Kottke, Narrative review. N/A

National Healthy of survey data

Worksite Program, (2013 \& 2015).

USA.

/A

2009)

(26)

$\begin{array}{ll}\text { (Pronk, 2009) } & \text { Literature review. NA } \\ (27) & \text { Database } \\ & \text { searches. }\end{array}$

\section{(Rinaldi-Miles \& Exploratory.}

Das, 2016)

Focus groups.

N/A
Universities (x3),

Midwestern \&

Southern USA.

Employees.
N/A

A comparison

Culture of health; employee perceptions of organisational support; PA.

show better leadership communication about WHP and flexible working $(12.1 \%$ \& $17.7 \%)$ than small $(3.2 \% \& 11.9 \%)$.

Employee-level perceived leadership support, coworker support, and employee engagement were statistically significant predictors of perceived organisational support for health at baseline and follow-up. PA not measured.

Corporate strategies designed to promote employee PA.

PA \& workplace factors.

Participation in PA, PA accessibility \& nominal group barriers.

technique

session.

Principles relevant for implementation of PA programs: 1) adopting a social-ecological model, 2) utilising evidence-based interventions 3) aligning interventions with best practices. Best practices for PA promotion 1) employee-centred culture/tailor programmes; 2) leadership; 3) measure and analyse.

Factors for consideration include workplace culture, social-ecological model, measurement and evaluation, and leadership. Top elements for effective workplace programs: 1) OC; 2) management support; 3) social norms; 4) employee advice, 5) formal program budgets/policies. Suggestions: better measuring and analysing of program outcomes.

Barriers to PA 1) lack of time and flexibility, 2) lack of departmental support. Supportive peers influences confidence to do PA. Cues for participation include creating a culture of wellness PA and centring PA opportunities around staff. 
(Ryde et al., 2020)

Cross-sectional. Interviews and focus groups.

(Sendall et al.,

Pre-post 2016) intervention.

Surveys.

(Strickland et al., Cross-sectional. 2015)

\section{Interviews and}

focus groups.
Three office-based None. organisations,

Sotland.

Employers \&

employees.

Six workplaces of

the TruckSafe

programme

Queensland,

Australia.

Employees (truck

drivers).

Health care and

labour union,

Washington, USA.

Employees

(hospital/retail).

\section{Legal reporting}

intervention.

Survey.

(32)

(Taylor et al., 2013)
Pre-post intervention. Survey. businesses, Texas,

USA.

Employees.

Five worksites (law, Six-month health \& education), USA. Employees. program.
Six-month

Acceptability, barriers, benefits and feasibility of PA in paid work time.

Implementing and evaluating PA promotion intervention.

Baseline, threemonth and sixmonth follow

up.

None.

Booster Break

Booster breaks

programme (15-min PA
PA behaviour, awareness, and workplace perceptions (e.g. norms).
Worksite culture, and policies that influence PA; barriers to participation in WHPS.

PA levels (IPAQ-LF), barriers, social support, programme feasibility and sustainability.

PA levels (IPAQ), social support, sedentary time, attendance.
Significant barriers to PA in paid work time, including workplace culture and norms resentment from collegues, no break culture, PA not accepted in workplace were barriers. The workplace is not currently an ideal setting for PA with significant cultural shifts required in order for such an initiative to work.

Percentage of employees who strongly agreed/agreed that PA was valued $(49 \%, 68 \%)$, encouraged $(11 \%, 36 \%)$, role modelled by supervisors $(13 \%, 41 \%)$, and adopted by other colleagues $(18 \%, 27 \%)$ increased from pre to post. Importance of collaboration with managers on implementing the intervention.

Few PA programs wellness programs offered to retail workers. Store retail workers were unawaure of initatiives and felt employers did not prioritise health. Contrast to those working in desk roles in same company who felt they had workplace and management support. Recommends participatory approaches.

Increases in PA from pre to post, including increases in step count. Booster Breaks can be adapted to suit participant and organisational needs. Changes were thought successful because of the SME culture focused around wellbeing.

Booster Breaks: (i) reduced stress and promoted enjoyment, (ii) increased health awareness, and (iii) enhanced workplace social interactions. Barriers: a) management support and role 
breaks) with

one year follow-

up.

(Towne et al.,

Pre-post

intervention.

Surveys.

(34)

surveys

(Veitch et al.,

Cross sectional.

Interviews.

(35)

(Viskum et al.,

Cluster RCT.

2015

Interviews.

(36)

(Watanabe et al., Longitudinal.

2018)

(37)

Questionnaire.

(Waterworth et Exploratory.

al., 2018)

Interviews.

(38)
University, Texas,

USA.

Staff.
Six-month

multifaceted

health \& PA

promotion

campaign.

Manufacturing None.

industry, Victoria,

Australia.

Managers \&

Insurance

providers.

Six office-based 20-week RCT:

workplace setting, strength

Denmark.

Employees.

Selected worksites,

Kanto, Tokyo.

Employees.

Small, medium

and large

businesses,

Western Australia.

Employees.

workplace.

None, but

baseline and

five-month

follow up.

Workplaces were on the

Healthier

Workplace WA

program.
Perceived organisational values and support for PA (among others).

training in the

Perceived

barriers/motivators of companies to offer PA, PA programmes available for employees. managers, colleagues and motivation and barriers to compliance. IPAQ).

Current workplace health culture; barriers and enablers to the implementation. modelling needed. Recommendations: a) employee \& employer representation and championing.

Non-significant increase in participants who disagreed that their school valued, supported and promoted PA over time. Perceptions of organisational support for PA overtime reduced. Recommendations: a) using multi-component approaches, b) tailoring to company/employee needs.

Insurers offered suggestions to motivate companies to offer PA: a) evidence base of PA. Insurers and managers agreed that culture of manufacturing industry acted as barrier to PA (not cultural norm/accepted).

Impact of workplace culture,

Worksite (size, location) and employee variables (e.g. PA initiatives (including PA) and
Colleagues and managers attitudes, support and acceptance and flexible working were motivators and barriers, dependent on attitudes.

$4-15 \%$ of variances explained by worksite variables, including parking/bike, signs/adverts, PA facilities, work rules, policies and programmes. PA influenced by effectiveness of workplace (e.g. written workplace policies).

Enablers/barriers: (1) existing business culture; (2) manager and peer support; (3) finance. PA not specifically noted but OC a primary influence on the implementation of health initiatives (including policies); existing cultures positive towards 
healthy behaviours more easily supported implementation.

\begin{tabular}{|c|c|c|c|c|c|}
\hline $\begin{array}{l}\text { (Wong et al., } \\
\text { 2014) } \\
(39)\end{array}$ & $\begin{array}{l}\text { Cross-sectional. } \\
\text { Diary } \\
\text { measurement \& } \\
\text { interviews. }\end{array}$ & $\begin{array}{l}\text { Bus drivers' } \\
\text { workday, Australia. } \\
\text { Employees } \\
\text { (drivers). }\end{array}$ & None. & $\begin{array}{l}\text { PA behaviour; opportunities } \\
\text { for PA during the workplace. }\end{array}$ & $\begin{array}{l}\text { Driving roles, shift work, short shift breaks } \\
\text { limiting factors for PA. Walking club and corporate } \\
\text { gym membership supported by management and } \\
\text { organisational commitment was high. PA } \\
\text { opportunities did not cater to all/ not employee- } \\
\text { centred. }\end{array}$ \\
\hline $\begin{array}{l}\text { (Yancey et al., } \\
\text { 2004) } \\
(40)\end{array}$ & $\begin{array}{l}\text { Process } \\
\text { evaluation. } \\
\text { Survey. }\end{array}$ & $\begin{array}{l}\text { Sites involved in } \\
\text { Worksite Wellness } \\
\text { program, CA, USA. } \\
\text { Employees. }\end{array}$ & $\begin{array}{l}\text { African } \\
\text { Americans } \\
\text { Building a } \\
\text { Legacy of } \\
\text { Health. }\end{array}$ & $\begin{array}{l}\text { Health status \& behaviours, } \\
\text { organisational commitment } \\
\text { to interventions and PA. }\end{array}$ & $\begin{array}{l}\text { Community service organisations more likely to } \\
\text { have formal PA contracts, and extent of overlap } \\
\text { believed to be because of alignment with } \\
\text { organisations main mission. }\end{array}$ \\
\hline
\end{tabular}

Additional table abbreviations: IPAQ-LF/SF (International Physical Activity Questionnaire - Long Form/Short Form); ROI (Return on Investment); WHP (Workplace Health Programme) 
Part of the Society for Transparency, Openness and Replication in Kinesiology (STORK)

\section{Preprint}

not peer reviewed

Table 2. Study characteristics of all reviewed studies

\begin{tabular}{|c|c|c|c|}
\hline Setting & $n$ & $\%$ & Study reference(s) \\
\hline \multirow[t]{2}{*}{ Private, public \& third sector office-based } & & & $(1,2,3,5,6,7,10,16,17,25,29,32$ \\
\hline & 16 & $40 \%$ & $36,37,38,40)$ \\
\hline Manufacturing industry & 1 & $3 \%$ & (35) \\
\hline transport industry (e.g. bus/ truck) & 1 & $3 \%$ & $(30,39)$ \\
\hline Military occupations (e.g. army/navy) & 2 & $5 \%$ & $(18)$ \\
\hline Educational office based (e.g. university) & 8 & $20 \%$ & $(8,12,13,15,20,22,28,34)$ \\
\hline Medical (e.g. hospital) & 2 & $5 \%$ & $(19,31)$ \\
\hline \multirow{4}{*}{$\begin{array}{l}\text { Multiple industries (e.g. blue collar/ private, } \\
\text { public and health) } \\
\text { Unspecified } \\
\text { Not applicable (a.k.a. reviews) }\end{array}$} & 2 & $5 \%$ & \\
\hline & 2 & $5 \%$ & $\begin{aligned} &(21, 3 \\
&(9,24)\end{aligned}$ \\
\hline & 6 & $15 \%$ & $(4,11,14,23,26,27)$ \\
\hline & $n=40$ & & \\
\hline Participants & $n$ & $\%$ & Study reference(s) \\
\hline \multirow{6}{*}{$\begin{array}{l}\text { Employees \& employers } \\
\text { Employees only } \\
\text { Employers only (e.g. managers) } \\
\text { Unspecified } \\
\text { Blank (a.k.a. reviews) }\end{array}$} & 15 & $38 \%$ & $\begin{array}{r}(1,2,3,5,7,9,13,16,18,25,29,31 \\
38,39,40) \\
(6,10,12,15,19,21,22,24,28,30\end{array}$ \\
\hline & 15 & $38 \%$ & $32,33,36,37)$ \\
\hline & 1 & $3 \%$ & (35) \\
\hline & 3 & $8 \%$ & $(8,17,34)$ \\
\hline & 6 & $15 \%$ & $(4,11,14,23,26,27)$ \\
\hline & $\mathrm{n}=40$ & & \\
\hline \multirow{2}{*}{$\begin{array}{l}\text { Research Methodology } \\
\text { Mixed-methods }\end{array}$} & $n$ & $\%$ & Study reference(s) \\
\hline & 9 & $23 \%$ & $\begin{array}{r}(1,5,8,10,13,20,22,29,38) \\
(2,3,6,7,12,15,18,28,29,31,35,\end{array}$ \\
\hline Qualitative & 13 & $33 \%$ & $(9,16,17,19,21,24,25,32,34,38)$ \\
\hline \multirow{3}{*}{$\begin{array}{l}\text { Quantitative } \\
\text { Reviews }\end{array}$} & 12 & $30 \%$ & 40) \\
\hline & 6 & $15 \%$ & $(4,11,14,23,26,27)$ \\
\hline & $\mathrm{n}=40$ & & \\
\hline Data Collection Method & $n$ & $\%$ & Study reference(s) \\
\hline \multicolumn{4}{|l|}{$\begin{array}{l}\text { Qualitative methods } \\
\text { Semi-structured intervie }\end{array}$} \\
\hline Semi-structured interviews \& & 4 & $19 \%$ & $(5,7,29,31)$ \\
\hline
\end{tabular}


Interviews

Focus groups

Staff logs/ open ended questions
$(1,2,3,6,13,15,18,22,35,36,38$,

$\mathrm{n}=22 *$

Quantitative methods

Online survey / questionnaire

Biometric measurements / health check

Accelerometer / pedometer data

$19 \quad 79 \%$

$3 \quad 13 \%$

$(1,5,8,9,10,16,17,20,21,22,24$,

$25,30,33,34,37,40)$

$28 \%$

$(19,25)$

$(13,39)$

$\mathrm{n}=23^{*}$

*Note, the 9 mixed-method studies and 3 quantitative studies using multiple methods have been double counted, totals will be larger than total number of studies reviewed

\section{Interventions}

All study designs are summarised in Table 3. Over half $(60 \%, n=24)$ of the reviewed literature captured behaviours and perceptions at a single time point and of these cross-sectional studies were most common $(n=15)$. In comparison, ten studies aimed to measure impact over time by taking prepost measurements, and of these five were randomised control trials. Collectively this indicates that a limited level of evidence against a control group exists and a general scarsity in measuring the impact of interventions on behaviour change across time. Five studies reported PA behaviour (Adams et al., 2017; Edmunds et al., 2013; Gilson et al., 2008; Hendriksen et al., 2016; Sendall et al., 2016). Three of these studies reported increases in walking or MVPA behaviour, yet PA measurement and recording was not consistent and increases were minimal. Adams et al. (2017), found minimal increases from baseline to follow up (16-21 months) in walking during the working day $(<1 \%)$ and only for those completing 1-30 minutes a day; those completing over 30 minutes of walking per day decreased $4.7 \%$ across this time (Adams et al., 2017). Other studies measured PA differently, reporting increases in the number of minutes spent completing MVPA (Hendriksen et al., 2016), or number of days spent active (Edmunds et al., 2013), although neither specifically measured PA in the workplace or workday. Further reporting of PA also varied; Hendriksen et al. (2016), reported increases in number of minutes, while Edmunds et al. (2013), reported increases as a percentage of respondents. Finally, a study showing no increases in the number of minutes truck drivers spent in MVPA over six-months used different work-specific PA measures (Sendall et al., 2016). Such inconsistency, and small number of studies reporting PA behaviours, makes consensus around effectiveness difficult. None of these studies demonstrated that PA behaviour change met, or was close to meeting, CMO guidelines. Similar conclusions are reflected through grey literature; a literature review conducted for the European Commission, 2017, found that few studies measured PA behaviour, and where measured interventions rarely move individuals towards the CMO guidelines 
(European Commission, 2017). Other industry reports indicate a need for a better understanding of programme effectiveness in influencing PA (CIPD, 2019) and also point towards the need for organisations to be collecting PA metrics (NICE, 2017).

Table 3. Study Design for reviewed studies

\begin{tabular}{|c|c|c|c|}
\hline Research Design & $\begin{array}{l}\text { Number } \\
\text { of studies }\end{array}$ & $\begin{array}{l}\text { Percentage of } \\
\text { studies }\end{array}$ & Study reference(s) \\
\hline Interventions & 17 & $44 \%$ & $\begin{array}{r}(1,2,3,4,10,12,13,16,19,20,28 \\
30,32,33,34,36,40)\end{array}$ \\
\hline Pre-post intervention & 5 & $13 \%$ & $(10,29,31,32,33)$ \\
\hline $\begin{array}{l}\text { Randomised control trial } \\
\text { (RCT) } \\
\text { Exploratory study / }\end{array}$ & 5 & $13 \%$ & $(13,16,19,20,35)$ \\
\hline process evaluation & 5 & $13 \%$ & $(6,21,28,38,40)$ \\
\hline Quasi-experimental study & 1 & $3 \%$ & (5) \\
\hline Case study design & 1 & $3 \%$ & (3) \\
\hline Cross-sectional study / & & & $(1,2,7,8,9,12,15,17,18,22,24$, \\
\hline case control & 15 & $38 \%$ & $29,31,35,39)$ \\
\hline Longitudinal study & 2 & $5 \%$ & $(25,36)$ \\
\hline Reviews & & & \\
\hline (narrative/systematic) & 6 & $15 \%$ & $(4,11,14,23,26,27)$ \\
\hline TOTAL: & 40 & & \\
\hline
\end{tabular}

The lack of consensus may be explained by variability in intervention type and length. Seventeen studies ran interventions (44\%, see Table 3), with seven of them capturing one data time point (Adams et al., 2017; Bailey et al., 2018; Banwell et al., 2016; Brinkley, McDermott, et al., 2017; George et al., 2014; Latza et al., 2018; Yancey et al., 2004) and the other ten capturing pre-post measurement. The most frequent length of intervention was six-months ( $n=6,35 \%$, see Table 1$)$ and type of PA provision provided through the interventions were diverse. PA provisions included active/fitness breaks (Taylor et al., 2010, 2013; Yancey et al., 2004), educational seminars (Bailey et al., 2018; Edmunds et al., 2013; Hendriksen et al., 2016; Sendall et al., 2016; Yancey et al., 2004), coaching (Edmunds et al., 2013; Hendriksen et al., 2016; Yancey et al., 2004), gym memberships (Wong et al., 2014), walking clubs and staff sport games (Adams et al., 2017; Brinkley, McDermott, et al., 2017; Gilson et al., 2008; Lemon et al., 2014; Wong et al., 2014), PA challenges (Lemon et al., 2014; Sendall et al., 2016; Towne et al., 2015), and goal setting (Edmunds et al., 2013). Other interventions promoted existing PA facilities, like stair use (Watanabe et al., 2018), developed signage (Towne et al., 2015; Watanabe et al., 2018), introduced champions (Adams et al., 2017; Latza et al., 2018), offered senior management endorsement (Bailey et al., 2018; Towne et al., 2015), or changed work policies (Watanabe et al., 2018). PA was more likely to be part of an intervention offered as a multi-component programme (e.g. along with smoking sensation or healthy eating) rather than alone $(n=10)$ (Bailey et al., 2018; Brinkley, McDermott, et al., 2017; Hendriksen et al., 2016; Latza et al., 
2018; Sendall et al., 2016; Towne et al., 2015; Waterworth et al., 2018; Yancey et al., 2004), linking to previous literature stating that employers find multi-faceted programmes appealing due to cost effectiveness and diversity (Towne et al., 2015). This variability in intervention indicates the complexity of workplace PA programmes and implies that a one size fits all approach is not applicable.

\section{Factors that influence PA programmes and interventions}

Key findings and themes from the reviewed studies were categorised to highlight the most prominent influences, barriers and facilitators of workplace PA programmes and interventions.

The majority of studies were conducted outside of the UK (68\%) and focused on office-based workplaces in the private, public and third $(n=16)$ or educational $(n=8)$ sectors (Table 2$)$. Data was frequently sampled from employees only $(n=15)$ or from both employees and employers $(n=15)$ (Table 2). There was roughly an even split between qualitative $(n=13)$ and quantitative $(n=12)$ methods used and nine studies used mixed-methods (Table 2). Interviews were the most common form of qualitative method used $(n=13)$ and surveys or questionnaires were the most frequently used quantitative method $(n=19)$.

\section{Workplace characteristics}

Workplace characteristics like company size and sector influenced existence of, implementation and maintenance of PA programmes, explored by seven studies (Banwell et al., 2016; Hammerback et al., 2015; Onufrak et al., 2018; Strickland et al., 2015; Veitch et al., 1999; Wong et al., 2014; Yancey et al., 2004). Company size was a limiting factor whereby small to medium sized enterprises (SMEs) experienced greater financial challenge, and SME employees reported limited opportunities, limited leadership support and less flexible working compared to larger organisations (Banwell et al., 2016; European Commission, 2017; Hammerback et al., 2015; Onufrak et al., 2018). SMEs were also less likely to prioritise employee health and wellbeing (British Safety Council, 2018) and act on an ad hoc basis rather than through formal policies and practices (CIPD, 2019).

Similarly, employees working in non-corporate or non-office-based roles reported fewer PA opportunities and less organisational support and commitment towards opportunities (Strickland et al., 2015; Veitch et al., 1999; Wong et al., 2014; Yancey et al., 2004). Workplace PA programmes seem to favour employees of larger and corporate-based roles within the same organisation; shop floor retail workers were less aware and had less access to PA opportunities compared to their officebased counterparts (Strickland et al. 2015). When PA opportunities are available job role demands, capacity and time impacted engagement across both office-based and shift work, acting as a barrier if time was sparse, or a facilitator if time was available (Adams et al., 2017; Banwell et al., 2016; Mazzola et al., 2017; Rinaldi-Miles \& Das, 2016; Wong et al., 2014). Studies focusing on the manufacturing and transport industries also highlight challenges for the employer of being able to cater to different shift patterns and job roles (CIPD, 2019; Nuffield Health, 2018; Veitch et al., 1999; Wong et al., 2014). The findings explored above indicate that engagement and availability to PA 
opportunities are influenced by different sectors, job roles and workplace locations. It suggests future research should continue to explore a wide variety of sectors to better understanding of how to cater PA opportunities for all types of workplaces and employees.

\section{Themes pertaining to $\mathrm{OC}$}

The following section highlights prominent areas exposed from the literature that were referred to as feeding into, impacting, or being a part of extant $\mathrm{OC}$ themes.

\section{Senior leadership.}

The role of senior leadership was commonly cited as influencing workplace PA programmes ( $n=21 ; 54 \%$ ) (Adams et al., 2017; Bailey et al., 2018; Brinkley, McDermott, et al., 2017; Chau et al., 2019; Cooper \& Barton, 2016; George et al., 2014; Gutermuth et al., 2018; Jia et al., 2017; Latza et al., 2018; Lemon et al., 2009; Payne et al., 2018; Pronk, 2009; Pronk \& Kottke, 2009; Sendall et al., 2016; Strickland et al., 2015; Taylor et al., 2013; Viskum et al., 2015; Waterworth et al., 2018) and also noted in grey literature through various industry reports (British Safety Council, 2018; Business in the Community, 2019; CIPD, 2019; European Commission, 2017; NICE, 2017; Nuffield Health, 2018). The role of senior leadership manifested itself in different ways; for example, the reviewed literature suggests that senior leadership needed to promote, role model, support and encourage participation in workplace PA programmes to aid employees to take part (Chau et al., 2019; Cooper \& Barton, 2016; George et al., 2014; Jia et al., 2017; Lemon et al., 2009; Lier et al., 2019; Payne et al., 2018; Pronk \& Kottke, 2009; Taylor et al., 2013; Waterworth et al., 2018). Employees felt senior leadership achieved this best through raising awareness and communicating about opportunities in a way that clearly established employees had permission to take part in them (Adams et al., 2017; Bailey et al., 2018; Brinkley, McDermott, et al., 2017; Flynn et al., 2018; Latza et al., 2018; Strickland et al., 2015). Conversely, lack of awareness, because of poor leadership communication was a perceived barrier to engagement (Strickland et al., 2015). Even where programmes were available to all employees, only certain staff groups became aware of, and thus, participated in them.

Other studies (Adams et al., 2017; Gilson et al., 2008; Jia et al., 2017; Viskum et al., 2015) noted that senior leadership support helped embed PA into normative behaviours. Perceived leadership buy-in and support for PA programmes was vital; employees repeatedly noted that if buyin was not seen from leadership this was a major barrier to PA and programme usage because they did not feel supported to change their behaviour (Adams et al., 2017; Bailey et al., 2018; Brinkley, McDermott, et al., 2017; Chau et al., 2019; Cooper \& Barton, 2016; George et al., 2014; Gilson et al., 2008; Jia et al., 2017; Latza et al., 2018; Lemon et al., 2009; Lier et al., 2019; Payne et al., 2018; Sendall et al., 2016; Strickland et al., 2015; Taylor et al., 2013; Viskum et al., 2015; Waterworth et al., 2018).

Authors of reviwed studies also noted the importance of senior leadership based on findings from employees (Blake \& Lloyd, 2008; Gutermuth et al., 2018; Pronk, 2009; Pronk \& Kottke, 2009). These studies did not explore the perspective of senior leadership however, to determine if they 
recgonised the impact that they played on others behaviours. Only one grey literature report asked these questions, finding that while some managers acknowledged that employee wellbeing fell under their responsibilities they often did not do much to support it, due to feeling under trained and illequipped (Business in the Community, 2019). This raises an interesting question surrounding the ability of senior leaders to support and promote PA, if they do not have the skills or understanding to do so. The lack of study of leaders perceptions around their responsibilities and capabilities to support their staff to be active suggests it is a viewpoint that needs further investigation. This viewpoint is important for understanding how employers and workplaces can better be supported to promote PA behaviours.

\section{Normative activities, practices, and social norms.}

Thirteen studies explored in detail the influence of normative workplace activities and practices, including those of leadership and colleagues, in determining employee PA behaviour (Brinkley, Freeman, et al., 2017; Edmunds et al., 2013; George et al., 2014; Gilson et al., 2008; Lemon et al., 2009; Michaels \& Greene, 2013; Rinaldi-Miles \& Das, 2016; Ryde et al., 2020; Viskum et al., 2015). George et al. (2014) noted that employees felt PA should be recognised as a legitimate workplace activity and be fully embedded into the $\mathrm{OC}$ in order for them to feel comfortable being active in working hours. The studies referenced above found that PA behaviour change was more likely if PA became part of the OC and normative practice (Edmunds et al., 2013) and were normalised by both managers and fellow employees (Gilson et al., 2008). Colleague's social normative behaviours (e.g. holding attitudes that being active in work hours was percieved as working less hard) influenced employees beliefs surrounding appropriate PA workplace behaviours and adoption of them (Brinkley, Freeman, et al., 2017; Lemon et al., 2009; Ryde et al., 2020), acting as either a facilitator or a barrier (Viskum et al., 2015). Colleagues also influenced employees confidence and comfort levels to engage in workplace PA, with supportive peers positively influencing confidence and attitudes (Rinaldi-Miles \& Das, 2016). Alternatively, employees felt it was difficult to engage in PA at work if it was considered abnormal (Gilson et al., 2008) or resented (Ryde et al., 2020) by peers.

\section{Acceptance, prioritisation, and alignment.}

In order to aid the success of workplace PA programmes, several studies specifically noted that a general culture of acceptance and open-mindedness facilitated this (Brinkley, Freeman, et al., 2017; Rinaldi-Miles \& Das, 2016; Taylor et al., 2010). As did PA specific encouragement and values (Sendall et al., 2016), positivity towards health (Jia et al., 2017; Waterworth et al., 2018), prioritisation of a culture of health that develops and supports PA opportunities (Brinkley, Freeman, et al., 2017; Chau et al., 2019; Cooper \& Barton, 2016; Hammerback et al., 2015; Lier et al., 2019; Strickland et al., 2015; Veitch et al., 1999) and alignment with the workplace's organisational identity (Flynn et al., 2018; Lemon et al., 2014; Michaels \& Greene, 2013; Pronk \& Kottke, 2009; Yancey et al., 2004). The level of acceptance in an organisation to support PA programmes and opportunities acted as either a facilitator, if acceptance was high, or the opposite, if acceptance was low, to employee engagement (Brinkley, Freeman, et al., 2017; Hendriksen et al., 2016; Jia et al., 2017; Payne et al., 2018; Rinaldi-Miles \& Das, 2016; Ryde et al., 2020; Sendall et al., 2016; Taylor et al., 2010; 
Waterworth et al., 2018). Overall, Taylor et al., (2010) indicated that an acceptance culture makes PA interventions more likely to be successful, while Waterworth et al. (2018) found that more accepting and health positive cultures have more success in implementing programmes than unaccepting cultures. Similarly, previous OC literature has referenced that behaviour is more likely to be sustained if it aligns with the OC rather than defying it (Alvesson, 2013; Mumby, 1994). In the present review, Yancey et al. (2004), found that the greater overlap with the company's main vision increased the likelihood of organisational commitment for PA promotion. Opposingly, if PA behaviour was considered a low priority this was interpreted negatively and created a barrier to participation (Chau et al., 2019; Hammerback et al., 2015), and coincided with either unsuccessful programmes (Brinkley, Freeman, et al., 2017; Cooper \& Barton, 2016) or low programme adherence and behaviour change (Strickland et al., 2015; Veitch et al., 1999). Lier et al. (2019) highlight that prioritising a culture of health is necessary for the success of any organisational wellness programme, a claim supported by The National Institute for Health and Care Excellence (NICE) quality statements (NICE, 2017).

\section{Policies, procedures (including flexible working).}

According to the NICE (2008a) recommendations, workplaces should engage in policy development and planning to support their employees to be active. Seven articles referenced the influence of PA promoting policies and procedures on PA behaviours with varied results (Crespo et al., 2011; Gutermuth et al., 2018; Lemon et al., 2014; Pronk \& Kottke, 2009; Rinaldi-Miles \& Das, 2016; Watanabe et al., 2018; Waterworth et al., 2018). Several articles stated formal written policies for PA promotion should exist to support behaviour change (Lemon et al., 2014; Watanabe et al., 2018), including PA being allocated a specific budget and resource (Pronk, 2009; Rinaldi-Miles \& Das, 2016) to ensure organisational commitment. Crespo et al. (2011) found that having PA promoting organisational policies in place were associated to higher MVPA at work. This was further supported by Waterworth et al. (2018) who claim that having policies and procedures in place made the implementation of health promoting initiatives in a workplace more likely to occur. Rinaldi-Miles \& Das (2016) agree and report that employees in their study perceived a lack of formal policies as a lack of administrative support, which reduced sustainable PA change. However, policy change is cited as the most challenging area to overcome due to resistance from administrators (Lemon et al., 2014). This raises the question as to what kind of support or further research is needed in order to reduce resistance and make policy change more likely in workplaces.

Policies to support PA promotion can vary in type; some examples include policies that explicitly allow time for worktime PA (Crespo et al., 2011) or provide the time through flexible working (NICE, 2008a; Nuffield Health, 2018). Flexible working was noted by six studies in the current review (Brinkley, Freeman, et al., 2017; Cooper \& Barton, 2016; Mazzola et al., 2017; Rinaldi-Miles \& Das, 2016; Viskum et al., 2015) as influencing employee opportunity to engage in workplace PA programmes. If flexible working patterns were available this tended to act as a facilitator to engagement (Viskum et al., 2015). Flexible working has also been associated with long-term participation in PA programmes (Brinkley, Freeman, et al., 2017), because it allowed employees to 
structure in more time for activity. In contrast, the other three reviewed studies cited a lack of flexible working as a barrier, because employees felt they did not have time or permission to fit PA around their work (Cooper \& Barton, 2016; Mazzola et al., 2017; Rinaldi-Miles \& Das, 2016). Overall, the research in the area of policies indicate that having them in place can aid engagement in and sustainability of PA opportunities. While there is limited research into different types of policies, it appears that flexible working has positive impact, leading employees to feel allowed to use their time to be active.

\section{Factors for improving PA programmes and interventions}

This review identified eight academic papers that highlighted factors that may help improve the likelihood of successful implementation and maintenance of workplace PA programmes.

\section{Ensure programmes have an evidence-base and develop guidance to support employers}

According to five studies (Bailey et al., 2018; Gutermuth et al., 2018; Pronk, 2009; Pronk \& Kottke, 2009; Veitch et al., 1999) and one grey literature report (British Safety Council, 2018), employers were more likely to commit to programmes if there was an evidence-base that supported the concept and linked PA engagement to employee health, productivity, reduced absenteeism and company ROI. This implies that said employers are located in workplaces that do not have an OC that actively prioritises or buys into employee health and PA, and thus will not organically engage in cultural change towards it unless presented with supportive evidence that demonstrates the benefits. In four studies (Bailey et al., 2018; Banwell et al., 2016; Lemon et al., 2014; Pronk \& Kottke, 2009), employers or authors stated that there was a need for guidance to be developed to support the development and implementation of programmes. Specifically, employers wanted guidance around aligning programmes to employee and organisational identity and needs (Banwell et al., 2016) and wanted an evidence-base demonstrating the impact of the activities they were selecting (Adams et al., 2017; Gutermuth et al., 2018; Pronk \& Kottke, 2009). Pronk \& Kottke (2009), suggested that in order to do this guidance around the principles of workplace PA promotion should be provided, focused on the types of programmes to implement (e.g. prioritising ones with an evidence base), and best practice around programme design, resource allocation and strategy development (Pronk \& Kottke, 2009). Grey literature reviews support the importance of guidance and resources for employers (European Commission, 2017; Nuffield Health, 2018), particularly around activity implementation and employee engagement. 


\section{Adopt an ecological and employee-centred approach}

Socio-ecological models have often been proposed (Sallis et al., 2008) as effective methods for implementing health behaviour change interventions, including PA, because they focus on individual, social and organisational levels of influence. In the current review three studies referred to the benefit of using a social-ecological approach when developing effective workplace PA programmes (Blake \& Lloyd, 2008; Pronk, 2009; Pronk \& Kottke, 2009). Two studies reported using such an approach (Lemon et al., 2009, 2014). For example, Lemon et al., (2014), activated a multi-level intervention which targeted individuals through PA champions and targeted social and organisational levels through employee advisory groups and organisational policy change.

More often than utilising socio-ecological approaches studies citied using an employeecentred approach $(n=10)$. This was referenced as putting employee needs at the heart of activity and programme development, and all ten studies reported that this approach positively impacted the usage and sustainability of workplace PA programmes (Adams et al., 2017; Chau et al., 2019; Latza et al., 2018; Lemon et al., 2014; Michaels \& Greene, 2013; Pronk \& Kottke, 2009; Rinaldi-Miles \& Das, 2016; Strickland et al., 2015; Towne et al., 2015; Wong et al., 2014). Autonomy was important to employees; they preferred to be consulted on activities rather than being provided with pre-selected options that did not consider their choices (Adams et al., 2017; British Safety Council, 2018; Chau et al., 2019; Latza et al., 2018; Rinaldi-Miles \& Das, 2016). Authors suggested that employees could provide invaluable feedback to employers around programmes which could be used to tailor activities to maximise usage and uptake (Lemon et al., 2014; Michaels \& Greene, 2013; Pronk \& Kottke, 2009; Strickland et al., 2015; Towne et al., 2015). It can be considered that using an employee-centred approach in this way aligns to adopting a socio-ecological model, because it caters to the individual factors of the model. Additionally, increased dialogue between employees and employers surrounding programme feedback can help engage social and organisational levels of influence. Hence, centring PA opportunities around employees can be considered not only an integral part of the socio-ecological approach, but may also be a feasible way in which to start to integrate socio-ecological approaches into the development of workplace PA programmes.

\section{Discussion}

There is growing acknowledgement of the importance of OC for the success of workplace PA programmes in academic literature. However, in order to further this topic area it is necessary to understand what is currently known through synthesis of existing literature. In the present review, we firstly aimed to identify gaps within the current literature around the role OC on workplace PA programmes. The review identifies a variety of factors that were found to influence and associate to workplace PA programmes. These include variability in measurement and reporting of PA metrics and programme types, the impact of workplace characteristics on PA programmes, and the influence of extant OC themes on PA programmes and PA behaviours. The current review also drew upon certain factors reported in the literature that improved the implementation of PA programmes, and 
these factors provide crucial information which underpin the applied recommendations for future research investigation detailed later in this review.

The first of the three factors that influenced workplace PA programmes was the variability in reporting of PA metrics and programme types. Within the current review only five studies out of the 39 reviewed here documented that PA behaviour measured and recorded as part of understanding and evaluating a PA programme, with the other 15 studies that ran PA programmes either not reporting or not capturing PA behaviour as a metric. Across the five studies that did capture it, measurement type was also inconsistent, varying between number of minutes active or days active to unspecified. Inconsistencies also existing with the ways in which they reported PA behaviour, some reporting raw figures at a single time point and others reporting pre to post percentage changes. Taken together these results indicate a shortage in the study of PA behaviour change, particularly the collection of PA data using high quality metrics, as previous literature has found (Commissaris et al., 2016; Mackenzie et al., 2018; Taylor et al., 2018). The lack of PA data collected impacts workplace PA programmes because it becomes impossible to determine if existing programmes are having the desired positive impact on PA. It is imperative that the evidence-base in this area be grown with a focus on developing high-quality studies that record and report PA behaviour before, during and after programme delivery. Additionally, in order to encourage study consistency and replicability, the PA metrics used should be reliable, valid and feasible for researchers and employers alike to implement as part of a real-time programme evaluation.

The second influencing factor on PA programmes was the role of workplace characteristics, like sector and job roles. Both of these were found to influence how likely an organisation is to have a PA programme in place, and subsequently employees awareness or engagement in the programme. Office-based, white collar organisations or job roles are more likely to have PA programmes in place that manual working professions or roles like retail, transport, and manufacturing. Where programmes are in place for employees in these roles, employees are less aware of their existence and less likely to use them because of the nature of their job roles (e.g. shift working). Finally, there is a general lack of study of PA provisions in professions that are not office based; the current review identified only six studies that specified a focus on PA opportunities for those working outside an office environment. This further highlights a lack of representation in the literature of employees and employers in non-corporate organisations and a potential bias through which the literature findings cater for corporate organisations only.

The third and final influencing factor upon PA programmes and PA promotion pertained to OC. As explored in the introduction, the importance of OC linked to the success of workplace PA programmes has steadily grown. As the current review identifies, most short listed articles were published within the last 9 years, with a spike in interest in the last three (since 2017), accounting for $41 \%$ of all reviewed articles. Four main elements that associate to extant OC themes were identified; senior leadership; normative behaviours; acceptance and prioritisation; and policies and procedures.

The results of the review indicate that these four elements have the potential to influence shared meaning and symbolism in an organisation and thus are all responsible for influencing behaviours associated to PA. Senior leadership was often described as influencing employees' perception of being allowed to part take in PA during the working day, and thus impacting actual PA 
behaviour. The way senior leadership influenced perception was often exemplified through their actions or behaviours such as clear communication about PA opportunities or their own engagement in or lack of engagement in PA behaviour through role modelling (e.g. Chau et al., 2019; Latza et al., 2018). A similar pattern in results occurred for the normative behaviours of colleagues. Overarching findings indicate that employees were driven to engage or disengage with workplace PA dependent on the actions and practices that their colleagues normally partook in (e.g. Brinkley, Freeman, et al., 2017; Gilson et al., 2008; Viskum et al., 2015). In this sense, both senior leadership and colleagues behaviours may be viewed as a symbolisation of how to (or how to not) engage with PA in working time. Consequently, if considering from Alvessons perspective of OC, this may provide a socially shared meaning of how accepted (or not) PA is within the workplace or to what extent the workplace prioritises engaging in PA (Alvesson, 2016). These meanings heavily influence whether employees decide to engage in $\mathrm{PA}$; further findings from the current review highlight this by reporting that employees did not engage in PA opportunities if colleagues and senior leadership were perceived as unsupportive, even if the opportunities were there (Strickland et al., 2015).

However, actions of entire corporations, extending beyond those of peers and leadership, and including the policies and procedures in place, are also responsible for influencing these shared meanings and symbols associated to healthy behaviours (Alvesson, 2016). The current review unearthed that employee PA programme adherence or PA behaviour change was low if PA behaviour was considered a low priority within the organisation (Chau et al., 2019; Strickland et al., 2015). Perceived priority of PA was often associated to general acceptance of PA on an organisational level, including having a wider culture of acceptance towards health (Waterworth et al., 2018). Prioritisation at an organisational level can also be portrayed through policies that exist to support the opportunities to be active. Studies reviewed here concluded that having PA promoting organisational policies in place, typically in the form of flexible working, supported PA behaviour change (e.g. Lemon et al., 2014; Watanabe et al., 2018) and associated to higher MVPA during work (Crespo et al., 2011), while a lack of formal policy acted as a barrier to PA (Rinaldi-Miles \& Das, 2016). Thus in addition to normative behaviours, the existence of acceptance culture, and organisational prioritisation and policies and procedures all influence employees PA behaviours. Similarly, this appears to be through the forms of symbolisation and meaning, whereby having policies in place symbolises to employees how acceptable it is to engage in PA during their working day.

The four elements explored above support utilising a socio-ecological model to understanding workplace PA behaviour change, because multiple levels of culture influence are considered (Sallis et al., 2008). Primarily these levels include social influences (e.g. colleagues and leadership) as well organisational influences (e.g. policies and acceptance). The results from this review also support that OC, explored through extant themes, does impact workplace PA. There are a number of key recommendations that can be provided based upon the literature findings, detailed below. These recommendations are aimed at both the researchers of workplace PA programmes and employers implementing them.

\section{1) The study of PA behaviour and organisational culture through socio-ecological and employee-centric approaches}

DOI: STORK.3389.XXXX
SportRxiv is free to access, but not to run. Please consider donating at www.storkinesiology.org/annual 26 
The uniqueness of organisations should be considered when developing or studying workplace PA programmes. That is, because multiple agents feed into an $\mathrm{OC}$ which influence what the organisations priority is (Alvesson, 2016), it is up to the organisation to determine which elements they feel are most significant to focus on. This may depend on whether said organisation utilises their leadership, their employees, or the entire corporation to drive organisational behaviour (Alvesson, 2016).

A suggested method through which to do this, would be to adopt a socio-ecological model, which targets and considers multiple organisational levels, and lends itself to more comprehensive intervention or programme development (Sallis et al., 2008). Such models are often used to understand and change health behaviours like PA because the role of social and organisational environments on behaviour is also captured (Sallis et al., 2008). For example, a socio-ecological model was used to positively influence active travel in Australia, by focusing on not just individual perspectives, but the role of the built environment (e.g. inaccessible sidewalks) that posed barriers to active travel (Owen et al., 2007). Socio-ecological approaches are also popular in the workplace because they tend to complement multi-facet programmes and have shown positive effects on behaviour (Allen, 2017). The findings in this review indicate that adopting an employee-centred approach was a successful way in which to intergrate a socio-ecological approach into the development of workplace PA programmes. Therefore, we recommended that employers consider adopting a socio-ecological approach that is employee-centred and specific to their organisational goals and needs when developing any workplace PA programmes. Further, in studying or researching workplace PA programmes researchers should adopt a socio-ecological model to accurately capture the role of $\mathrm{OC}$ and the multiple agents that impact workplace PA behaviour change.

\section{2) Improve measurement and evaluation of workplace PA programmes}

Variability in intervention type and measurement of PA behaviour adds to the ambiguity about how impactful workplace PA programmes are, and if it is worth employers investment. Within their literature review, the European Commission pinpoint that few studies actually determine how PA interventions benefit businesses because information linking PA behaviour and business outcomes is not measured (European Commission, 2017). Within their literature reviews Pronk (2009) and Pronk \& Kottke (2009) conclude that organisations running programmes can themselves contribute to and build the current evidence-base by implementing measurement and evaluation of their programmes and capturing data on measures like those listed above, but that currently it is not often done. Similarly, the current review identified that PA behaviour changes, particularly those aligned to the CMO guidelines, are often not captured because pre to post measurement is not implemented. Improving the consistency of PA programme measurement and evaluation will support the evidencebase underpinning programme impact, and allow wider conclusions to be drawn about the association of PA programmes on other work-related factors (e.g., presenteeism or absenteeism) which may encourage employer buy-in. More consistent measurement of programme outcomes, including usage of nationally used metrics, can also help improve the quality of data captured.

DOI: STORK.3389.XXXX
SportRxiv is free to access, but not to run. Please consider donating at www.storkinesiology.org/annual 
In regards to studying OC qualitative methodologies are considered a more appropriate way of exploring its complex nature (Alvesson, 2013; Martin, 1992). Quantitative measures, such as selfreport questionnaires, have been labelled as ineffective for capturing the full essence of $\mathrm{OC}$ and are recommended not to be used (Schein, 2006). Therefore, to capture information on the role of OC on PA programmes it is suggested that this be captured through appropriate qualitative methods. Nevertheless, in order to capture this alongside programme outcomes like PA behaviour, it is recommended that employers implementing data collection adopt mixed-methods research (MMR). Applying both qualitative and quantitative methods (MMR) allows data to be captured in a way that best addresses complex research questions (Smith et al., 2012) and can enhance study validity and complement the strengths of each methods (Moran et al., 2011). In addition to this, it is considered appropriate for understanding complex interventions, particularly those implemented in real-world settings with multiple layers of influence (Morgan, 2007), and for understanding the breadth of reality (Smith et al., 2012). Thus, it is recommended that employers or researchers implement effective data collection around programme outcomes, using MMR research designs to capture outcomes like PA behaviour and the role of OC.

\section{3) Develop tangible guidance and tools to support employers in developing workplace PA opportunities and programmes}

Employers expressed, through the reviewed literature (Bailey et al., 2018; Banwell et al., 2016; Lemon et al., 2014; Pronk \& Kottke, 2009), wanting support, in the format of guidance and tools, which they can utilise to support their employees to be physically active. Such guidance and tools will in part be supported by further measurement and evaluation of PA programmes and their influence of PA behaviour and other factors of interest to organisations or employers. Workplace PA programmes captured through academic literature begin to shape this, but could be expanded to include wider industry-led perspectives captured through grey literature. Basing guidance and tools on data captured beyond academic literature is important for several reasons. Firstly, grey literature offers information at an earlier stage than academic literature, given the lag between research and publication (Pappas \& Williams, 2011). Secondly incorporating grey literature into academic research can counteract biases that may occur through academic publication, such as the tendency to publish positive results over negative ones (Pappas \& Williams, 2011). This literature review synthesises academic literature, and some grey literature, however no grey literature that focused specifically on workplace PA programmes or OC. To extend the present work, it is recommended that a more indepth review be conducted within grey literature, potentially through industry-wide data collection. This can be used to inform and build the evidence-base towards how OC impacts PA programmes and better understand how workplace PA programmes not captured through academia are being measured and evaluated.

\section{Strength \& Limitations}

A strength of the present review is its specific focus on workplace PA programmes and OC to

DOI: STORK.3389.XXXX
SportRxiv is free to access, but not to run. Please consider donating at www.storkinesiology.org/annual

28 
provide relevant and tangible recommendations for employers and real world implementation of workplace PA programmes. We chose to purposefully review studies focusing on workplace PA and the role $\mathrm{OC}$ in order to synthesis the literature in this area, an action that has not been done to date. Choosing to keep our review specific has thus provided valuable insights into the important role OC can have and key next steps to further the evidence-base and effectively implementing PA programmes in workplaces. The present review also uses the systematic PRISMA guidelines, with clear inclusion and exclusion criteria, allowing it to be replicated and extended. Limitations may lie around capturing studies through this process, based on terminology variations (e.g. for PA behaviour) or the omission of potentially valuable findings published in articles that were not in English.

\section{Conclusion}

The literature studied here shows that $\mathrm{OC}$ has an important role to play in the implementation, uptake and sustainability of workplace PA programmes, and even before that stage, impacts workplace PA opportunities or overall behaviours. It also highlights inconsistences in the measurement of workplace PA programmes and offers clear recommendations of how to improve the quality of measurement. Recommendations presented here have implications for both practice and future research, and are targeted directly towards employers and researchers supporting employers. We recommendation that further study of PA workplace programmes and OC occur using socioecological and employee-centred approaches, accounting for unique employee and organisational needs, goals and aims. In order to continue the building of an evidence-base in this area that informs PA programme delivery and supports employers to make evidence-informed decisions, a second recommendation focuses on improving measurement and evaluation of PA programmes. As part of it, we encourage the use of methods appropriate for capturing programme outcome measures (e.g. PA behaviour) and OC, such as the use of MMR. The third recommendation brings the first two together and suggests employers be provided with clear guidance of how to design, implement and measure PA programmes in a way that is accessible and is translatable.

All reviewed literature was published prior to the COVID-19 pandemic however the current recommendations remain relevant to this topic area going forward. Based on the recommendations and to conclude, we encourage further investigation into this area. This will aid our understanding of not just the role OC plays, but the steps that need to be taken to empower organisations and employers and researchers to support their employees PA behaviour in the best way possible.

\section{Contributions}

Contributed to conception and design: $\mathrm{AL}, \mathrm{CW}$

Contributed to acquisition of data: AL

Contributed to analysis and interpretation of data: $\mathrm{AL}$ 
Drafted and/or revised the article: $\mathrm{AL}, \mathrm{MW}, \mathrm{CW}$

Approved the submitted version for publication: Al, MW, CW

\section{Acknowledgements}

The lead author would like to thank ukactive for their support of this research, and the co-authors for their author contributions to the manuscript.

\section{Funding information}

This report is independent research written by the leader author as part of her professional doctorate studies. The leader authors doctorate is funded through her professional organisation, ukactive. The views expressed in this publication are those of the author and not necessarily those of the funding organisation. The funding organisation was not involved in the design of the study, collection, analysis of interpretation of data, or the writing. The lead author and co-authors have competing interests, financial or otherwise.

\section{Data and Supplementary Material Accessibility}

All data generated or analysed during this study are included in the article and reference list. Databases searched, inclusion and exclusion criteria are presented in Figure 1. No additional data or supplementary material accessibility exists.

\section{REFERENCES}

[1] *Adams, E. J., Chalkley, A. E., Esliger, D. W., \& Sherar, L. B. (2017). Evaluation of the implementation of a whole-workplace walking programme using the RE-AIM framework. BMC Public Health, 17(1). https://doi.org/10.1186/s12889-017-4376-7

[2] Aldana, S. G., Anderson, D. R., Adams, T. B., Whitmer, R. W., Merrill, R. M., George, V., \& Noyce, J. (2012). A Review of the Knowledge Base on Healthy Worksite Culture. Journal of Occupational and Environmental Medicine, 54(4), 414-419. https://doi.org/10.1097/JOM.0b013e31824be25f

[3] Allen, J. (2017). Transforming organizational cultures to support good health. In M. P. O'donnell (Ed.), Health Promotion in the Workplace (5th ed., pp. 633-648).

[4] Allender, S., Foster, C., Scarborough, P., \& Rayner, M. (2007). The burden of physical activityrelated ill health in the UK. Journal of Epidemiology and Community Health, 61(4), 344-348. https://doi.org/10.1136/jech.2006.050807

[5] Alvesson, M. (2013). Understanding organizational culture (K. Smy, R. Eley, \& R. Leigh (eds.); 2nd ed.). SAGE.

[6] Alvesson, M. (2016). Organizational culture and health. In Healthy at Work: Interdisciplinary Perspectives (pp. 13-25). Springer International Publishing. https://doi.org/10.1007/978-3-319- 
32331-2_2

[7] Babic, M. J., Parker, P. D., Lubans, D. R., Lonsdale, C., \& Professor Chris Lonsdale, A. (2017). Domain-specific physical activity and mental health: A meta-analysis. Am J Prev Med., 52(5), 653666.

[8] *Bailey, M. M., Coller, R. K., \& Pollack Porter, K. M. (2018). A qualitative study of facilitators and barriers to implementing worksite policies that support physical activity 11 Medical and Health Sciences 1117 Public Health and Health Services. BMC Public Health, 18(1). https://doi.org/10.1186/s12889-018-6045-x

[9] *Banwell, C., Sargent, G., Dixon, J., \& Strazdins, L. (2016). A cultural economy approach to workplace health promotion in Australian small and medium sized workplaces: a critical qualitative study. Critical Public Health, 29(1), 100-109. https://doi.org/10.1080/09581596.2017.1414152 [10] BHF. (2016). Health a Work - Economic evidence report for workplace health - Health at Work. https://www.bhf.org.uk/publications/health-at-work/health-at-work---economic-evidence-report [11] Bize, R., Johnson, J. A., \& Plotnikoff, R. C. (2007). Physical activity level and health-related quality of life in the general adult population: A systematic review. Preventive Medicine, 45(6), 401-415. https://doi.org/10.1016/J.YPMED.2007.07.017

[12] *Blake, H., \& Lloyd, S. (2008). Influencing organisational change in the NHS: lessons learned from workplace wellness initiatives in practice. Quality in Primary Care, 16(6), 449-455.

http://www.ncbi.nlm.nih.gov/pubmed/19094421

[13] Brakenridge, C. L., Healy, G. N., Hadgraft, N. T., Young, D. C., \& Fjeldsoe, B. S. (2018). Australian employee perceptions of an organizational-level intervention to reduce sitting. Health Promotion International, 33(6), 968-979. https://doi.org/10.1093/heapro/dax037

[14] Breuer, C. (2014). Economic benefits of physical activity 1.3 Economic benefits of Physical Activity. https://www.researchgate.net/publication/261377581

[15] *Brinkley, A., Freeman, J., McDermott, H., \& Munir, F. (2017). What are the Facilitators and Obstacles to Participation in Workplace Team Sport? A Qualitative Study. AIMS Public Health, 4(1), 94-126. https://doi.org/10.3934/publichealth.2017.1.94

[16] *Brinkley, A., McDermott, H., \& Munir, F. (2017). Team Sport in the Workplace? A RE-AIM Process Evaluation of 'Changing the Game.' AIMS Public Health, 4(5), 466-489. https://doi.org/10.3934/publichealth.2017.5.466

[17] British Safety Council. (2018). Not just free fruit: wellbeing at work: A literature review. https://www.britsafe.org/campaigns-policy/not-just-free-fruit-wellbeing-at-work/

[18] Business in the Community. (2019). Business in the Community Annual Report 2018/2019. https://www.bitc.org.uk/report/business-in-the-community-annual-report-2019/

[19] Cahalin, L. P., Kaminsky, L., Lavie, C. J., Briggs, P., Cahalin, B. L., Myers, J., Forman, D. E., Patel, M. J., Pinkstaff, S. O., Arena, R., Cambece, J. A., Office, L., \& Beverly, P. C. (2015). Development and Implementation of Worksite Health and Wellness Programs: A Focus on Non-Communicable Disease ScienceDirect. https://doi.org/10.1016/j.pcad.2015.04.001

[20] Cancelliere, C., Cassidy, J. D., Ammendolia, C., \& Côté, P. (2011). Are workplace health promotion programs effective at improving presenteeism in workers? a systematic review and best evidence synthesis of the literature. BMC Public Health, 11(1), 395. https://doi.org/10.1186/1471- 
2458-11-395

[21] *Chau, J., Engelen, L., Kolbe-Alexander, T., Young, S., Olsen, H., Gilson, N., Burton, N., Bauman, A., \& Brown, W. (2019). "In Initiative Overload": Australian Perspectives on Promoting Physical Activity in the Workplace from Diverse Industries. International Journal of Environmental Research and Public Health, 16(3), 516. https://doi.org/10.3390/ijerph16030516

[22] CIPD. (2019). Health and Well-being at Work.

[23] Commissaris, D. A. C. M., Huysmans, M. A., Mathiassen, S. E., Srinivasan, D., Koppes, L. L. J., \& [24] Hendriksen, I. J. M. (2016). Interventions to reduce sedentary behavior and increase physical activity during productive work: A systematic review. In Scandinavian Journal of Work, Environment and Health (Vol. 42, Issue 3, pp. 181-191). Nordic Association of Occupational Safety and Health. https://doi.org/10.5271/sjweh.3544

[25] Conn, V. S., Hafdahl, A. R., Cooper, P. S., Brown, L. M., \& Lusk, S. L. (2009). Meta-analysis of workplace physical activity interventions. American Journal of Preventive Medicine, 37(4), 330-339. https://doi.org/10.1016/j.amepre.2009.06.008

[26] *Cooper, K., \& Barton, G. C. (2016). An exploration of physical activity and wellbeing in university employees. Perspectives in Public Health, 136(3), 152-160.

https://doi.org/10.1177/1757913915593103

[27] *Crespo, N. C., Sallis, J. F., Conway, T. L., Saelens, B. E., \& Frank, L. D. (2011). Worksite physical activity policies and environments in relation to employee physical activity. American Journal of Health Promotion, 25(4), 264-271. https://doi.org/10.4278/ajhp.081112-QUAN-280

[28] Das, B. M., Mailey, E., Murray, K., Phillips, S. M., Torres, C., \& King, A. C. (2016). From sedentary to active: Shifting the movement paradigm in workplaces. Work, 54(2), 481-487.

https://doi.org/10.3233/WOR-162330

[29] Davies, D. S. C., Atherton, F., McBride, M., \& Calderwood, C. (2019). UK Chief Medical Officers' Physical Activity Guidelines. In Department of Health and Social Care (Issue September).

https://www.gov.uk/government/publications/physical-activity-guidelines-uk-chief-medical-officersreport

[30] Department of Health. (2005). Choosing Activity: people, their communities, local government, voluntary agencies and business a physical activity action plan.

[31] Ding, D., Lawson, K. D., Kolbe-Alexander, T. L., Finkelstein, E. A., Katzmarzyk, P. T., Van Mechelen, W., \& Pratt, M. (2016). The economic burden of physical inactivity: a global analysis of major non-communicable diseases. Www.Thelancet.Com, 388. https://doi.org/10.1016/S01406736(16)30383-X

[32] Dugdill, L., Brettle, A., Hulme, C., Mccluskey, S., \& Long, A. (2008). Workplace Physical Activity Interventions: a Systematic Review Workplace Physical Activity Interventions: a Systematic Review Background. International Journal of Workplace Health Management, 1(1), 20-40.

[33] *Edmunds, S., Stephenson, D., \& Clow, A. (2013). The effects of a physical activity intervention on employees in small and medium enterprises: A mixed methods study. Work, 4, 39-49. https://scihub.tw/10.3233/WOR-121523

[34] Ekelund, U., Steene-Johannessen, J., Brown, W. J., Fagerland, M. W., Owen, N., Powell, K. E., Bauman, A., Lee, I. M., Ding, D., Heath, G., Hallal, P. C., Kohl, H. W., Pratt, M., Reis, R., Sallis, J., 
Aadahl, M., Blot, W. J., Chey, T., Deka, A., ... Yi-Park, S. (2016). Does physical activity attenuate, or even eliminate, the detrimental association of sitting time with mortality? A harmonised metaanalysis of data from more than 1 million men and women. The Lancet, 388(10051), 1302-1310. https://doi.org/10.1016/S0140-6736(16)30370-1

[35] European Commission. (2017). Physical activity at the workplace, Literature review and best practice case studies: a final report to the European Commission - Study.

https://op.europa.eu/en/publication-detail/-/publication/9fc2b8a0-e537-11e7-9749-

01aa75ed71a1/language-en/format-PDF/source-56006094

[36] European Commission. (2018). Special Eurobarometer on sport and physical activity | 472. https://ec.europa.eu/sport/news/2018/new-eurobarometer-sport-and-physical-activity_en

[37] Flint, S. W., Crank, H., Tew, G., \& Till, S. (2017). "It's not an Obvious Issue, Is It?" Office-Based Employees' Perceptions of Prolonged Sitting at Work. Journal of Occupational and Environmental Medicine, 59(12), 1161-1165. https://doi.org/10.1097/JOM.0000000000001130

[38] *Flynn, J. P., Gascon, G., Doyle, S., Matson Koffman, D. M., Saringer, C., Grossmeier, J., Tivnan, V., Terry, P., \& Johnson, J. \&. (2018). Supporting a Culture of Health in the Workplace: A Review of Evidence-Based Elements. American Journal of Health Promotion, 32(8), 1755-1788.

https://doi.org/10.1177/0890117118761887

[39] FSB. (2020). Health and wellbeing: Boosting productivity and resilience in your business | FSB, The Federation of Small Businesses. https://www.fsb.org.uk/active.html

[40] FT. (2019). Health at Work - Britains Healthiest Workplaces. https://www.vitality.co.uk/mediaonline/britains-healthiest-workplace/pdf/2019/health-at-work-

2019_uk.pdf?la=en\&hash=E87840347CDEFAA86C144EDF16C6053243F490AA

[41] *George, E. S., Kolt, G. S., Rosenkranz, R. R., \& Guagliano, J. M. (2014). Physical Activity and Sedentary Time: Male Perceptions in a University Work Environment. American Journal of Men's Health, 8(2), 148-158. https://doi.org/10.1177/1557988313497217

[42] *Gilson, N., Mckenna, J., \& Cooke, C. (2008). Experiences of Route and Task-Based Walking in a University Community: Qualitative Perspectives in a Randomized Control Trial Article in Journal of physical activity \& health $\cdot$. Journal of Physical Activity \& Health, 5(1), 176-182.

https://doi.org/10.1123/jpah.5.s1.s176

[43] Graveling, R., Crawford, J., Cowie, H., Amati, C., \& Vohra, S. (2008). A review of workplace interventions that promote mental wellbeing in the workplace. In Institute of Occupational Medicine. http://www.crd.york.ac.uk/crdweb/ShowRecord.asp?LinkFrom=OAI\&ID =12010005953

[44] *Gutermuth, L. K., Hager, E. R., \& Porter, K. P. (2018). Using the CDC's worksite health scorecard as a framework to examine worksite health promotion and physical activity. Preventing Chronic Disease, 15(6). https://doi.org/10.5888/pcd15.170463

[45] *Hammerback, K., Hannon, P. A., Harris, J. R., Clegg-Thorp, C., Kohn, M., \& Parrish, A. (2015). Perspectives on workplace health promotion among employees in low-wage industries. American Journal of Health Promotion, 29(6), 384-392. https://doi.org/10.4278/ajhp.130924-QUAL-495 [46] *Hendriksen, I. J. M., Snoijer, M., De Kok, B. P. H., Van Vilsteren, J., \& Hofstetter, H. (2016). Effectiveness of a Multilevel Workplace Health Promotion Program on Vitality, Health, and WorkRelated Outcomes. Journal of Occupational and Environmental Medicine, 58(6), 575-583. 
https://doi.org/10.1097/JOM.0000000000000747

[47] Huijg, J., Gebhardt, W., Verheijden, M., van de Zouwe, N., de Vries, J., Middlekoop, B., \& Crone, M. (2015). Factors Influencing Primary Health Care Professionals' Physical Activity Pr...: Discovery Service for University of Portsmouth. International Society of Behavioral Medicine, 22, 32-50. [48] *jia, Y., Gao, J., Dai, J., Zheng, P., \& Fu, H. (2017). Associations between health culture, health behaviors, and health-related outcomes: A cross-sectional study. PloS One, 12(7), e0178644. https://doi.org/10.1371/journal.pone.0178644

[49] *Latza, U., Hampel, E., Wiencke, M., Prigge, M., Schlattmann, A., \& Sommer, S. (2018). Introducing occupational health management in the German Armed Forces. Health Promotion International, 33, 938-945. https://doi.org/10.1093/heapro/dax035

[50] *Lemon, S. C., Wang, M. L., Wedick, N. M., Estabrook, B., Druker, S., Schneider, K. L., Li, W., \& Pbert, L. (2014). Weight gain prevention in the school worksite setting: Results of a multi-level cluster randomized trial. Preventive Medicine, 60, 41-47. https://doi.org/10.1016/J.YPMED.2013.12.010

[51] *Lemon, S. C., Zapka, J., Li, W., Estabrook, B., Magner, R., \& Rosal, M. C. (2009). Perceptions of worksite support and employee obesity, activity, and diet. American Journal of Health Behavior, 33(3), 299-308. http://www.ncbi.nlm.nih.gov/pubmed/19063651

[52] *Lier, L. M., Breuer, C., \& Dallmeyer, S. (2019). Organizational-level determinants of participation in workplace health promotion programs: a cross-company study. BMC Public Health, 19(1), 268-276. https://doi.org/10.1186/s12889-019-6578-7

[53] Mackenzie, K., Such, E., Norman, P., \& Goyder, E. (2018). The development, implementation and evaluation of interventions to reduce workplace sitting: a qualitative systematic review and evidencebased operational framework. BMC Public Health, 18(1), 833. https://doi.org/10.1186/s12889-0185768-z

[54] Malik, S. H., Blake, H., \& Suggs, L. S. (2014). A systematic review of workplace health promotion interventions for increasing physical activity. British Journal of Health Psychology, 19(1), 149-180. http://eprints.nottingham.ac.uk/38444/1/BJHP - Malik et al Final.pdf

[55] Marshall, A. L. (2004). Challenges and opportunities for promoting physical activity in the workplace. Journal of Science and Medicine in Sport , 7(1), 60-66.

https://www.jsams.org/article/S1440-2440(04)80279-2/pdf

[56] Martin, J. (1992). Cultures in organizations : three perspectives. Oxford University Press.

[57] *Mazzola, J. J., Moore, J. T., \& Alexander, K. (2017). Is work keeping us from acting healthy? How workplace barriers and facilitators impact nutrition and exercise behaviors. Stress and Health, 33(5), 479-489. https://doi.org/10.1002/smi.2731

[58] Mellor, N., \& Webster, J. (2013). Enablers and challenges in implementing a comprehensive workplace health and well-being approach. International Journal of Workplace Health Management, 6(2), 129-142. https://doi.org/10.1108/IJWHM-08-2011-0018

[59] Merrill, R. M., Aldana, S. G., Pope, J. E., Anderson, D. R., Coberley, C. R., Grossmeier, J. J., \& Whitmer, R. W. (2013). Self-Rated Job Performance and Absenteeism According to Employee Engagement, Health Behaviors, and Physical Health. https://doi.org/10.1097/JOM.0b013e31827b73af [60] *Michaels, C. N., \& Greene, A. M. (2013). Worksite Wellness: Increasing Adoption of Workplace Health Promotion Programs. Health Promotion Practice, 14(4), 473-479. 
[61] Moher, D., Liberati, A., Tetzlaff, J., Altman, D. G., \& Group, T. P. (2009). Preferred Reporting Items for Systematic Reviews and Meta-Analyses: The PRISMA Statement. PLoS Medicine, 6(7), e1000097. https://doi.org/10.1371/journal.pmed.1000097

[62] Moran, A. P. ;, Matthews, J. ;, \& Kirby, K. (2011). Whatever happened to the third paradigm? Exploring mixed methods research designs in sport and exercise psychology. Qualitative Research in Sport, 3(3), 362-369. https://doi.org/10.1080/2159676X.2011.607843

[63] Morgan, D. L. (2007). Paradigms Lost and Pragmatism Regained Methodological Implications of Combining Qualitative and Quantitative Methods. Journal of Mixed Methods Research, 1(1), $48-76$. https://doi.org/10.1177/2345678906292462

[64] Mumby, D. (1994). Cultures in Organizations: Three Perspectives. In Academy of Management Review (Vol. 19, Issue 1). https://doi.org/10.5465/amr.1994.9410122014

[65] NICE. (2008a). Recommendations | Physical activity in the workplace | Guidance | NICE.

[66] NICE. (2008b). Workplace health promotion: how to encourage employees to be physically active.

[67] NICE Public Health Guidance, 13. www.nice.org.uk

[68] NICE. (2017). Healthy Workplaces: Improving Employee Mental and Physical Health and Wellbeing: Quality Standard.

https://doi.org/https://www.nice.org.uk/guidance/qs147/resources/healthy-workplaces-improvingemployee-mental-and-physical-health-and-wellbeing-pdf-75545484547525

[69] Nuffield Health. (2018). A Healthier Workplace: How employers can reduce physical inactivity. [70] O'leary, L., Taggart, | Laurence, \& Cousins, W. (2018). Healthy lifestyle behaviours for people with intellectual disabilities: An exploration of organizational barriers and enablers. J Appl Res Intellect Disabil, 31, 122-135. https://doi.org/10.1111/jar.12396

[71] *Onufrak, S. J., Watson, K. B., Kimmons, J., Pan, L., Kettel Khan, L., Hee Lee-Kwan, S., \& Park, S. (2018). Intervention: Nutrition/Physical Activity Worksite Food and Physical Activity Environments and Wellness Supports Reported by Employed Adults in the United States, 2013. American Journal of Health Promotion, 32(1), 96-105. https://doi.org/10.1177/0890117116664709

[72] Owen, N., Cerin, E., Leslie, E., duToit, L., Coffee, N., Frank, L. D., Bauman, A. E., Hugo, G., Saelens, B. E., \& Sallis, J. F. (2007). Neighborhood Walkability and the Walking Behavior of Australian Adults. American Journal of Preventive Medicine, 33(5), 387-395.

https://doi.org/10.1016/j.amepre.2007.07.025

[73] Pappas, C., \& Williams, I. (2011). Grey literature: Its emerging importance. Journal of Hospital Librarianship, 11(3), 228-234. https://doi.org/10.1080/15323269.2011.587100

[74] *Payne, J., Cluff, L., Lang, J., Matson-Koffman, D., \& Morgan-Lopez, A. (2018). Elements of a Workplace Culture of Health, Perceived Organizational Support for Health, and Lifestyle Risk. American Journal of Health Promotion, 32(7), 1555-1567. https://doi.org/10.1177/0890117118758235 [75] Pereira, M. J., Coombes, B. K., Comans, T. A., \& Johnston, V. (2015). The impact of onsite workplace health-enhancing physical activity interventions on worker productivity: a systematic review. Occupational and Environmental Medicine, 72(6), 401-412. https://doi.org/10.1136/oemed2014-102678

[76] Plotnikoff, R. C., Prodaniuk, T. R., Fein, A. J., \& Milton, L. (2005). Development of an Ecological Assessment Tool for a Workplace Physical Activity Program Standard. Health Promotion Practice, 6(4), 
453-463. https://doi.org/10.1177/1524839904263730

[77] *Pronk, N. P. (2009). Physical Activity Promotion in Business and Industry: Evidence, Context, and Recommendations for a National Plan. In Journal of Physical Activity and Health (Issue 6). www.physicalactivityplan.org

[78] *Pronk, N. P., \& Kottke, T. E. (2009). Physical activity promotion as a strategic corporate priority to improve worker health and business performance. Preventive Medicine, 49(4), 316-321.

https://doi.org/10.1016/j.ypmed.2009.06.025

[79] Public Health England. (2016). Health matters: getting every adult active every day.

https://www.gov.uk/government/publications/health-matters-getting-every-adult-active-every-

day/health-matters-getting-every-adult-active-every-day

[80] Public Health England. (2020). Activities for kids: Change4Life.

https://www.nhs.uk/change4life/activities

[81] Puig-Ribera, A., Martínez-Lemos, I., Giné-Garriga, M., González-Suárez, Á. M., Bort-Roig, J., Fortuño, J., Muñoz-Ortiz, L., McKenna, J., \& Gilson, N. D. (2015). Self-reported sitting time and physical activity: interactive associations with mental well-being and productivity in office employees. BMC Public Health, 15(1), 72. https://doi.org/10.1186/s12889-015-1447-5

[82] Retamal, M. C., Hinckson, E., Castillo-Retamal, M., \& Hinckson, E. A. (2011). Measuring physical activity and sedentary behaviour at work: A review. Work, 40, 345-357.

https://doi.org/10.3233/WOR-2011-1246

[83] *Rinaldi-Miles, A. I., \& Das, B. M. (2016). Cost and culture: Factors influencing worksite physical activity across three universities. Work, 55(3), 703-713. https://doi.org/10.3233/WOR-162426

[84] *Ryde, G. C., Atkinson, P., Stead, M., Gorely, T., \& Evans, J. M. M. (2020). Physical activity in paid work time for desk-based employees: a qualitative study of employers' and employees' perspectives. https://doi.org/10.1186/s12889-020-08580-1

[85] Sallis, J., Owen, N., \& Fisher, E. (2008). Ecological models of health behavior. In K. Glanz, B. K. Rimer, \& K. Viswanath (Eds.), Health Behavior and Health Education: Theory, Research and Practice (4th ed., pp. 465-487). Jossey-Bass Publishers.

[86] Scarborough, P., Bhatnagar, P., Wickramasinghe, K., Allender, S., Foster, C. E., \& Rayner, M. (2011). The Economic Burden of Ill Health due to Diet, Physical Inactivity, Smoking, Alcohol and Obesity in the UK: An Update to 2006-07 NHS Costs. Journal of Public Health, 33(4), 527-535.

[87] Schein, E. H. (2006). So How Can You Assess Your Corporate Culture? In J. V. Gallos (Ed.), Organization Development (1st ed., pp. 614-633). Jossey-Bass.

[88] Schein, E. H. (2010). Organizational culture and leadership. Jossey-Bass.

[89] *Sendall, M. C., Crane, P., Mccosker, L. K., Biggs, H. C., Fleming, M., \& Rowland, B. (2016). Workplace interventions to improve truck drivers' health knowledge, behaviours and self-reported outcomes. 25.

[90] Smith, B., Sparkes, A. C., Kirkby, C. \&, Smith, B., Sparkes, A. C., Phoenix, C., \& Kirkby, J. (2012). Qualitative research in physical therapy: A critical discussion on mixed-methods. Physical Therapy Review, 17(6), 374-381. http://opus.bath.ac.uk/48720/1/Physical_therapy_review_Post_Print.pdf [91] Sport England. (2019). Active Lives Adult Survey: May 18/19 Report. https://sportenglandproduction-files.s3.eu-west-2.amazonaws.com/s3fs-public/2020-01/active-lives-adult-may-18-19- 
report_1.pdf?ehS5I7YBm3YeLHgNwXLmUSbTZPENafJY

[92] Sport England. (2020). We Are Undefeatable | Sport England.

https://www.sportengland.org/campaigns-and-our-work/we-are-undefeatable

[93] Squires, H., Rick, J., Carroll, C., \& Hillage, J. (2012). Cost-effectiveness of interventions to return employees to work following long-term sickness absence due to musculoskeletal disorders. Journal of Public Health, 34(1), 115-124. https://doi.org/10.1093/pubmed/fdr057

[94] *Strickland, J. R., Eyler, A. A., Purnell, J. Q., Kinghorn, A. M., Herrick, C., \& Evanoff, B. A. (2015). Enhancing Workplace Wellness Efforts to Reduce Obesity: A Qualitative Study of Low-Wage Workers in St Louis, Missouri, 2013-2014. Prev Chronic Dis, 12, 140405. https://doi.org/10.5888/pcd12.140405 [95] *Taylor, W. C., King, K. E., Shegog, R., Paxton, R. J., Evans-Hudnall, G. L., Rempel, D. M., Chen, V., \& Yancey, A. K. (2013). Booster Breaks in the workplace: participants' perspectives on healthpromoting work breaks. Health Education Research, 28(3), 414-425.

https://doi.org/10.1093/her/cyt001

[96] *Taylor, W. C., Shegog, R., Rempel, D., Pappas Baun, M., Chen, V., Rempel, D. M., Bush, C. L., Green, T., \& Hare-Everline, N. (2010). The Booster Break program: Description and feasibility test of a worksite physical activity daily practice. Work, 37, 433-443. https://doi.org/10.3233/WOR-2010-1097 [97] Taylor, W. C., Suminski, R. R., Das, B. M., Paxton, R. J., \& Craig, D. W. (2018). Organizational Culture and Implications for Workplace Interventions to Reduce Sitting Time Among Office-Based Workers: A Systematic Review. Frontiers in Public Health, 6, 263.

https://doi.org/10.3389/fpubh.2018.00263

[98] *Towne, S., Anderson, K., Smith, M., Dahlke, D., Kellstedt, D., Purcell, N., \& Ory, M. (2015). Changing organizational culture: using the CEO cancer gold standard policy initiatives to promote health and wellness at a school of public health. BMC Public Health. https://doi.org/10.1186/s12889015-2186-3

[99] *Veitch, J., Clavisi, O., \& Owen, N. (1999). Physical activity initiatives for male factory workers: gatekeepers' perceptions of potential motivators and barriers. Australian and New Zealand Journal of Public Health, 23(5), 505-510. https://doi.org/10.1111/j.1467-842X.1999.tb01307.x

[100] *Viskum, T., Bredahl, G., Saervoll, C. A., Kirkelund, L., Sjøgaard, G., \& Andersen, L. L. (2015). When Intervention Meets Organisation, a Qualitative Study of Motivation and Barriers to Physical Exercise at the Workplace. The Scientific World Journal. https://doi.org/10.1155/2015/518561 [101] Wagstaff, C., \& Burton-Wylie, S. (2018). Organisational culture in sport: A conceptual, definitional and methodological review The psychosocial factors affecting the development of overuse injuries in rhythmic gymnastics View project Stress and wellbeing in Sport View project. Sport \& Exercise Psychology Review, 14(1), 32-52.

[102] *Watanabe, K., Kawakami, N., Otsuka, Y., \& Inoue, S. (2018). Associations among workplace environment, self-regulation, and domain-specific physical activities among white-collar workers: A multilevel longitudinal study. International Journal of Behavioral Nutrition and Physical Activity, 15(1). https://doi.org/10.1186/s12966-018-0681-5

[103] *Waterworth, P., Pescud, M., Chappell, S., Davies, C., Roche, D., Shilton, T., Ledger, M., Slevin, T., \& Rosenberg, M. (2018). Culture, management and finances as key aspects for healthy workplace initiatives. Health Promotion International, 33(1), 162-172. https://doi.org/10.1093/heapro/daw068 
[104] WHO. (2008). Preventing Noncommunicable Diseases in the Workplace through Diet and Physical Activity WHO/World Economic Forum Report of a Joint Event. World Health Organization / World Economic Forum. http://www.who.int/dietphysicalactivity/WHOWEF_report_JAN2008_FINAL.pdf [105] *Wong, J. Y. L., Gilson, N. D., Bush, R. A., \& Brown, W. J. (2014). Patterns and perceptions of physical activity and sedentary time in male transport drivers working in regional Australia.

Australian and New Zealand Journal of Public Health, 38(4), 314-320. https://doi.org/10.1111/17536405.12214

[106] *Yancey, A. K., Lewis, L. B., Sloane, D., \& Mccarthy, W. J. (2004). Leading by example: a local health department-community collaboration to incorporate physical activity into organizational practice. https://www.researchgate.net/publication/6563551

*reviewed articles 